\title{
Factor analysis versus multi-dimensional scaling: binary choice roll-call voting and the US Supreme Court
}

\author{
Timothy J. Brazill ${ }^{\mathrm{a}, *}$, Bernard Grofman ${ }^{\mathrm{b}}$ \\ a Department of Sociology, Mercer University, 1400 Coleman Avenue, Macon, GA 31207, USA \\ b School of Social Sciences, University of California, Irvine, Irvine, CA, USA
}

\begin{abstract}
We evaluate factor analysis and multi-dimensional scaling (MDS) as tools for the analysis of voter decisions over a series of dichotomous choices. We simulate binary voting data with a known form and illustrate that standard factor analyses of these types of data yield additional artifactual dimensions. This effect may be exacerbated by the choice of inter-voter measures of similarity used as input. These results call in question the conclusions of others based on standard factor analyses of empirical voting data from the US Supreme Court. We demonstrate that MDS methods produce more parsimonious descriptions of these data. (C) 2002 Elsevier Science B.V. All rights reserved.
\end{abstract}

Keywords: Factor analysis; Multi-dimensional scaling; Ideology

\section{Introduction}

Multi-dimensional scaling (MDS, see Torgerson, 1958; Shepard, 1962a, 1962b, 1974; Kruskal, 1964a, 1964b; Shepard et al., 1972a, 1972b; Coxon, 1982; Hubert and Arabie, 1988; Kruskal and Wish, 1978) has been an important tool in mathematical psychology, mathematical anthropology, and social network analysis for understanding the structure of choices, cognitions, and social proximity. In contrast, in political science (and more mainstream sociology) MDS has been very little used, while for decades factor analysis (Hotelling, 1933; Cattell, 1952; Guttman, 1954a; Harman, 1960; Kim and Mueller, 1978) has been the standard analytic tool for modeling the dimensional structure of political or social attitudes, as well as being used for various other purposes, such as creating composite variables to deal with problems of multi-collinearity (Alwin, 1973).

\footnotetext{
* Corresponding author. Tel.: +1-478-301-2955; fax: +1-478-301-2438.

E-mail address: brazill_tj@mercer.edu (T.J. Brazill).
} 
Within political science, there are numerous empirical studies using factor analysis to map the ideological/issue/policy space locations of parties (e.g. Budge and Fairlie, 1983; Budge et al., 1987; Macdonald et al., 1991), voters (e.g. Enelow and Hinich, 1984), members of legislative bodies, such as the US House or Senate (MacRae, 1970; MacRae and Goldner, 1958; Clausen, 1973; Wilcox and Clausen, 1991), and members of multi-judge courts, such as the Supreme Court (e.g. Ulmer, 1960, 1970; Schubert, 1965, 1974; Rohde and Spaeth, 1976). However, the recent seminal work of Poole and Rosenthal $(1984,1991,1997)$ on roll-call voting in the US Congress has brought MDS ideas to the attention of political scientists, though these authors and those who have critiqued their work (such as Koford, $1990,1991,1994)$ do not appear to be familiar with empirical applications of MDS in disciplines other than political science.

There is, for instance, a long history of the comparison of these analytic approaches in psychology and education research, primarily through the work of Louis Guttman (1958, 1966, 1982, 1954a, 1954b; Lingoes and Guttman, 1967; Schlesinger and Guttman, 1969; but see also, e.g. Guttman and Shoham, 1982; Levin et al., 1983; Masolavty et al., 2001). As Guttman (1982) indicates, however, knowledge of the relationship between these approaches seems to have been slow to diffuse even in that field. To remedy this situation, he first points out that in a certain sense, "in the spatial analysis of correlation matrices" (p. 491), factor analysis is a special case of smallest space analysis (a variant of MDS). The approaches have a number of things in common, including the motivation to represent variables as points in a low dimensional space where distance between them is inversely proportional to their similarity. There are, however, a number of important differences, Guttman (1982) adds. Two of these differences are important for our discussion here, namely, that in most cases factor analysis will produce estimates of higher dimensionality than MDS techniques, and that MDS techniques generally allow for a broader array of similarity coefficients that may be meaningfully used as input (p. 492).

Lack of knowledge of these methodological differences and the resulting disparity between the conclusions reached using factor analysis and those using MDS techniques have led to controversy in the analysis of voting behavior. Factor analytic analyses of congressional roll-call voting invariably find a complex multi-factor structure to the choice patterns of members of congress (see, e.g. Clausen, 1973; Wilcox and Clausen, 1991), while recent work using sophisticated MDS techniques (Poole and Rosenthal, 1997) has suggested that there is one overwhelmingly predominant factor in historical patterns of congressional roll voting and that a two-dimensional representation accounts for almost all the variance. ${ }^{1}$ Similarly, Schubert's (1974, Chapter 7) work on the Supreme Court using a form of MDS (smallest space analysis) argues for one fewer dimension than does his earlier work on factor analysis of court decisions (Schubert, 1965, 1974, Chaps. 1-6), while more recent authors who use factor analysis (Dudley and Ducat, 1986; Ducat and Dudley, 1987) also find more dimensions in Supreme Court decisions than those who use MDS (Grofman and Brazill, in press). Similarly, some authors who use factor analysis to study the dimensionality of voters in the US have found separate loadings for pro-Democrat and pro-Republican dimensions

\footnotetext{
${ }^{1}$ In seeking to account for the differences between the results of the two methods, Koford $(1990,1991,1994)$ has criticized the Poole and Rosenthal work as understating the "true" number of dimensions (for rejoinder see Poole and Rosenthal, 1991).
} 
rather than a unidimensional structure with strong Democratic supporters on one side and strong Republican supporters on the other (Weisberg, 1980).

We offer in this paper a comparison of the properties of factor analysis and MDS as tools for the analysis of voter behavior. ${ }^{2}$ We limit ourselves to voting contexts involving a series of dichotomous choices by some set of voters, such as decisions to sustain or reverse lower court decisions by a multi-judge court of appeals (e.g. the US Supreme Court). While this type of voting situation will be the focus in this paper, it should be clear that our general arguments could be extended to similar data arising out of different contexts. Network analysts, for instance, often collect binary affiliation or membership data, indicating involvement in or attendance at some number of social organizations or events (Davis et al., 1941; Homans, 1951). Spatial analyses of this type of data would certainly raise the same types of questions we address here.

Our two central questions are, first, when can factor analysis and MDS be expected to give different answers to the question of how many dimensions are inherent in such a data structure; and second, which method can be expected to get us (closer to) the "right" answer.

We shall approach these questions in three ways.

First, we begin with one theoretical explication of the decision processes that might underlie binary choice roll-call voting data. This model corresponds to what we might call "ideology". This form of unidimensionality arises from what is known in psychology as the Coombsian unfolding model (Coombs, 1964), i.e. from what economists (Black, 1958; Arrow, 1961) call single-peakedness.

We show that a perfect Guttman scale (Guttman, 1944, 1950a, 1950b), commonly used as the hallmark of unidimensionality for pairwise voting data (MacRae, 1970), can be generated by ideological decision processes.

Second, we look at simulations involving binary data with a known structure to identify the situations under which factor analysis and MDS can, in principle, be expected to recover the "true" dimensions in the data, and the extent to which the two methods can be expected to yield different results. We show that:

(1) When the binary data perfectly fits a unidimensional Guttman scale, MDS recovers the unidimensionality with no error, but factor analysis invariably generates extra bogus dimensions: a minimum of one extra dimension and sometimes considerably more than one extra dimension when there are a large number of distinct voting patterns and heterogeneity in the data (see Guttman, 1958, 1982). Moreover, when graphed, the two-dimensional factor analysis solution to data that is a perfect Guttman scale generates a U-shaped partly backward bending curve (referred to by Guttman, 1954b as a circumplex). This is purely a statistical artifact, but has been wrongly interpreted by some scholars as support for the existence of an "extremism" dimension or as evidence for the presence of more than one non-orthogonal dimension (Schubert, 1965; Chapter 8, pp. 248-254).

(2) When the data are generated by a two-dimensional unfolding model, then MDS perfectly recovers the dimensionality of the space but tends to overweight the importance of the

\footnotetext{
${ }^{2}$ Roll-call data can also, in principle, be analyzed via other statistical techniques such as correspondence analysis (Weller and Romney, 1990), but for reasons of both space and manageability we shall confine our comparisons to those between MDS and factor analysis.
} 
first dimension by projecting onto it outcomes that are a weighted average of the two "true" axes. In contrast, as with the one-dimensional case, for two-dimensional data generated from an unfolding model, factor analysis will almost inevitably generate more than two-dimensions.

(3) Even when noise is added to binary choice data, MDS still more accurately recovers the number of dimensions, even though the goodness of fit will be reduced.

(4) For dichotomous choice (voting) data, the ability to recover the true dimensionality of the data can be improved for MDS (and factor analysis, slightly) if, instead of using the square matrix of Pearson correlations as our input we use instead the square matrix of pairwise agreements (or simple matching coefficients).

Third, we turn to empirical analyses, and generate both factor analyses and MDSs of actual voting data from the US Supreme Court for each of the fifteen natural courts that heard a substantial number of cases during the period 1953-1991. We examine differences in the results we get using the two methods and determine which method seems more appropriate for these data. By providing direct comparisons of the two methods for the Supreme Court data sets, we are able to better appreciate why authors who have differed in their choice of statistical tools have also been led to quite different substantive conclusions about the dimensionality and the underlying structure of their data.

\section{A path to unidimensionality: the "ideology" model}

We wish to identify a theoretical structure for what we commonly think of as a unidimensional pattern in binary (roll-call) voting data, namely a perfect Guttman scale (Guttman, 1944, 1950a, 1950b). First, we imagine a set of nine voters/judges making decisions, say, about whether to accept/uphold or reject some particular proposal/legal decision.

In this model of unidimensionality we posit that voters can be thought of as having "ideal points" located on a left-right continuum (i.e. a line). We assume that if the decision is to reject any given proposal then there is some "reversion point" (status quo) for that proposal which will characterize the outcome in the absence of a positive decision on that proposal, and that both the proposals and their reversion points can also be taken to be points on this line. The reversion points need not be the same for different proposals. Consider the vote on any proposal. It generates a pairwise choice between the proposal and its reversion point. To decide how each voter behaves in this pairwise choice, we posit that voters compare their own location (ideal point) on the line with that of each of the alternatives (i.e. the proposal, on the one hand, and the reversion point, on the other) and choose whichever is closest to the voter's own ideal point.

These assumptions are a form of the standard Downsian proximity model in one-dimension (Downs, 1957). It is well-known that these assumptions about the space of alternatives and about the nature of voter choice imply that voters have what economists call "single-peaked preferences" (Black, 1958; Arrow, 1961). ${ }^{3}$ It is also well-known that, when simple proximity is the decision-rule used by voters, then, in one-dimension, if we know the midpoint of the location of the two alternatives (here the proposal and the reversion point), voters

\footnotetext{
${ }^{3}$ The implication does not work in the reverse direction.
} 
with ideal points to one side of that midpoint will vote for the proposal and voters with ideal points to the opposite side of that midpoint will vote against it.

We can illustrate these points quite simply. Consider nine voters with ideal points distributed on a line, with the proposal $(\mathrm{P})$ and its reversion point $(\mathrm{R})$ also shown as points on the line, and with the midpoint $\left(\mathrm{m}_{1}\right)$ of the line segment RP also indicated in the diagram.

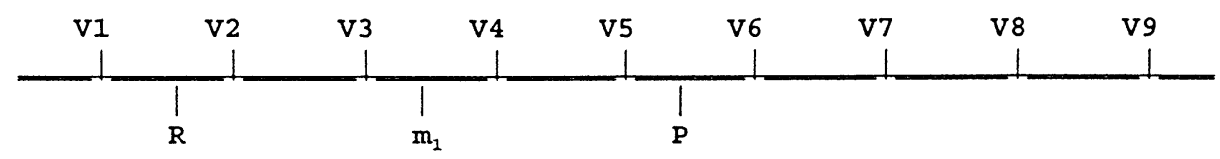

It is easy to see that voters 1, 2 and 3 will vote against the proposal and voters 4-9 will vote for it. Such a pattern of voting corresponds to what we might readily identify as "ideology", i.e. voters on the right support the rightist status quo, voters on the left prefer change in a leftward direction. It is also easy to see that if we reverse the locations of $\mathrm{R}$ and $\mathrm{P}$, the midpoint between them does not change but the preferences of voters does. Now it is 1,2 and 3 who vote for the proposal and voters 4-9 who vote against it. It is straightforward to extend this analysis to other midpoint locations. For any midpoint, if $\mathrm{R}$ is to the left of $\mathrm{P}$, the voters with ideal points to the right of the midpoint of the RP line segment will vote against the proposal while voters to the left of the midpoint will vote for it; conversely, if $\mathrm{R}$ is to the right of $\mathrm{P}$, the voters with ideal points to the left of the midpoint of the RP line segment will vote against the proposal while voters to the right of the midpoint will vote for it. (For simplicity we will not worry about the essentially trivial complication caused by ties).

Let us now assume that we have nine such proposals, each of which has the support of at least one of the voters, and each of which reflects a unique combination of voters. In the diagram below each vote is identified only by its midpoint, and in each case $\mathrm{R}$ is to the left of $\mathrm{P}$.

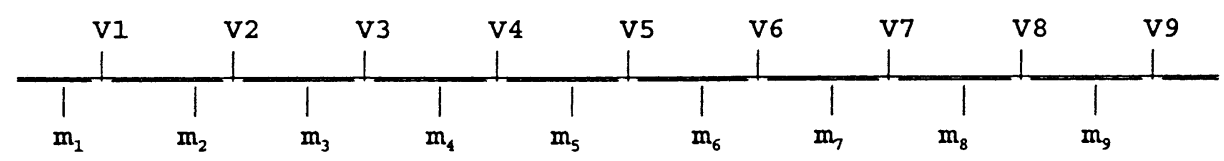

We can represent this pattern of voting in matrix form. Let 1 be a vote for the proposal and 0 be a vote for the reversion point. Let columns be voters arrayed according to the location of their ideal points on the line (from left to right) and with rows designating proposals. Under the above assumptions, the possible patterns are shown in Table 1. This pattern is a perfect Guttman scale (Guttman, 1944, 1950a, 1950b).

There is, however, more than one way to get a Guttman scalable pattern in binary voting data. Another form corresponds to what, in the context of the Condorcet Jury theorem literature (Black, 1958; Grofman, 1975), has been called "judgments”(Grofman et al., 1983; Grofman and Feld, 1988) or "epistemic preferences" (Coleman and Ferejohn, 1986), and has also been investigated in the fields of mathematical anthropology and psychology as "consensus" (Romney et al., 1986, 1987; Batchelder and Romney, 1988). This second form of unidimensionality arises most commonly from evaluations of stimuli according to a common metric, but subject to perceptual error, e.g. a situation where there are true-false questions which differ in their difficulty level and subjects who differ in their knowledge and/or competence. Further exploration of this model, however, is beyond the scope of this paper. 
Table 1

Perfect Guttman scale (simplex) pattern (reversion point to the left of the proposal)

\begin{tabular}{lllllllll}
\hline Voter 1 & Voter 2 & Voter 3 & Voter 4 & Voter 5 & Voter 6 & Voter 7 & Voter 8 & Voter 9 \\
\hline 1 & 1 & 1 & 1 & 1 & 1 & 1 & 1 & 1 \\
0 & 1 & 1 & 1 & 1 & 1 & 1 & 1 & 1 \\
0 & 0 & 1 & 1 & 1 & 1 & 1 & 1 & 1 \\
0 & 0 & 0 & 1 & 1 & 1 & 1 & 1 & 1 \\
0 & 0 & 0 & 0 & 1 & 1 & 1 & 1 & 1 \\
0 & 0 & 0 & 0 & 0 & 1 & 1 & 1 & 1 \\
0 & 0 & 0 & 0 & 0 & 0 & 1 & 1 & 1 \\
0 & 0 & 0 & 0 & 0 & 0 & 0 & 1 & 1 \\
0 & 0 & 0 & 0 & 0 & 0 & 0 & 0 & 1 \\
\hline
\end{tabular}

\section{Simulations in one-dimension}

We wish to study the effects of factor analysis and MDS on simulated binary choice data with a known dimensional structure-binary data that is a perfect Guttman scale, i.e. a complete simplex pattern with no error. ${ }^{4}$ Of course, there are a multiplicity of variants of factor analysis and a multiplicity of variants of MDS. In particular, there are both metric and non-metric versions of MDS. While we have completed analyses with both metric and non-metric MDS, the results were so similar that we will present only metric MDS (MMDS) results to conserve space. For the factor analyses in this paper we use standard principal components procedures and extract unrotated factors. We do not regard these particular choices as consequential since the effects of option choices within the two methods are, as we shall see, totally dwarfed in their consequences by the dramatic general differences between factor analysis and MDS in their estimates of dimensionality. ${ }^{5}$ For both factor analysis and MDS we use the output of the SYSTAT 5.0 (Wilkinson, 1990) statistical package.

If we submit the one-dimensional, perfectly Guttman-scaleable data for a nine member voting body presented in Table 1 to a standard Principal Components factor analysis we achieve the results in Fig. 1. Here, the voters' records (columns in our matrix) have been treated as "variables" to be scaled. They are plotted according to their factor loadings on the first two factors. There are a number of interesting effects of such an analysis. First, only eight points are scaled. Voter 9 has been omitted because she has an extreme ideological position and the lack of variance in her voting record (a column of all 1's) prevents us from producing phi coefficients (the binary equivalent of Pearson product moment correlations) between it and those of the other voters, as is necessary for standard factor analyses (for an alternative factor analytic approach to dichotomous variables, see Christofferson, 1975).

\footnotetext{
${ }^{4}$ We make no effort in this paper to provide general mathematical descriptions of either factor analysis or MDS since there are numerous works (e.g. Harman, 1960 for factor analysis; Kruskal and Wish, 1978 for MDS) which do so. Rather, much like the work of Weisberg (1974), though we reach different conclusions, our focus is on the implications that choosing one or the other of these statistical tools has on the substantive conclusions reached in empirical research on voting, attitudes or cognition.

${ }^{5}$ In particular, we have performed additional analyses using other options in the factor analysis program, e.g. varimax rotations.
} 


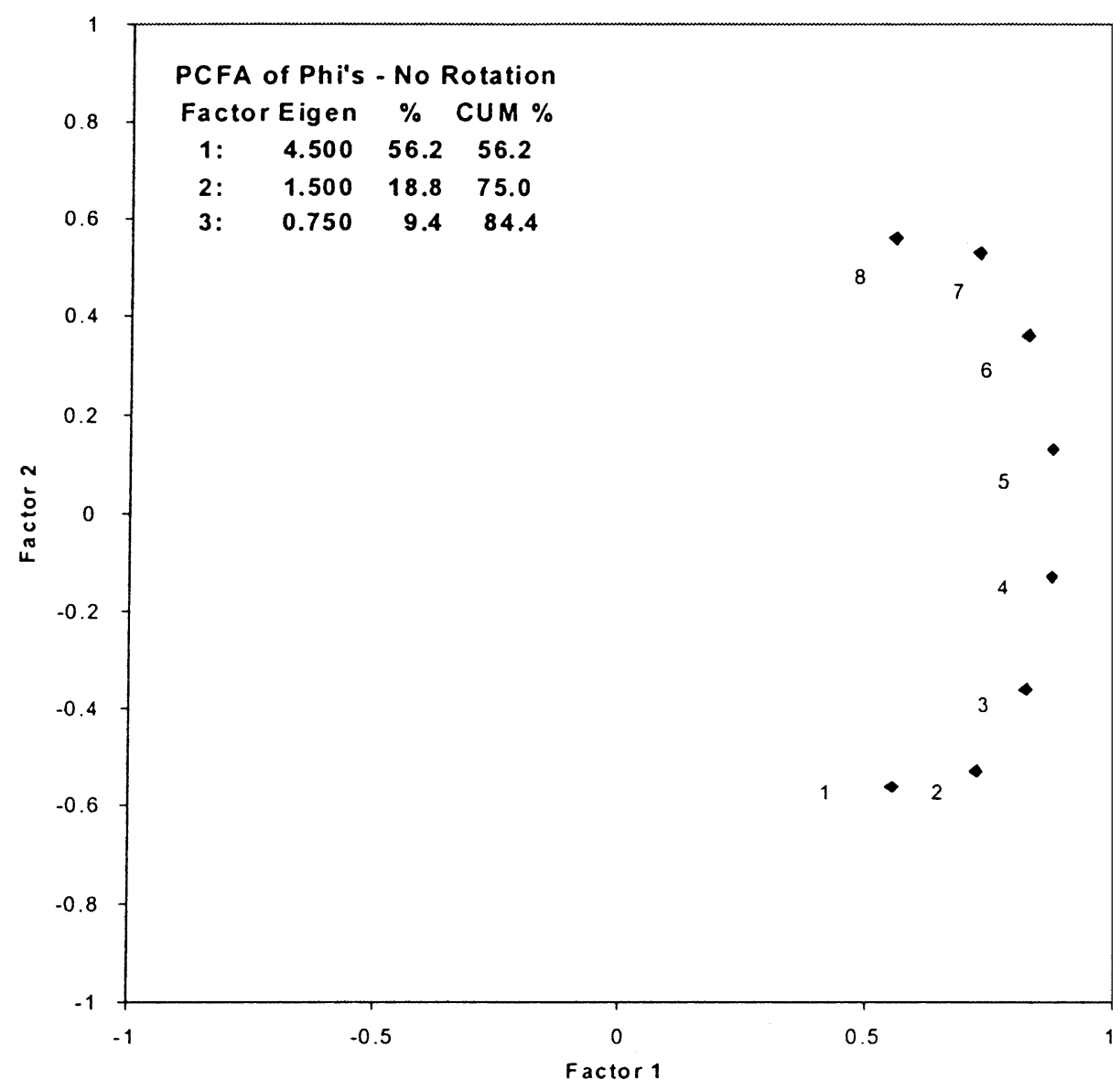

Fig. 1. Principal components factor analysis of phi coefficients—no rotation.

This standard pre-production of correlations (or covariances) between variables (here, the voting records) also has other effects, as well be described later in this paper. Secondly, the first two eigenvalues are greater than one. Based on Kaiser's (1974) criterion, described as "one of the most popular criteria for addressing the number of factors question" (Kim and Mueller, 1978, p. 43), which advocates simply retaining those factors with eigenvalues $>1$, it would seem two factors are necessary to explain this unidimensional structure. But note that these two factors collectively explain only $75 \%$ of the variance in the correlation matrix. Further, the voters' factor loadings are arranged in a "U" or "horseshoe" pattern in the two-dimensions. ${ }^{6}$

This "horseshoe effect" is a well-known, methodological artifact in the scaling literature (e.g. Weller and Romney, 1990; Gifi, 1990). As explicated by Van Schuur and Kiers (1994,

\footnotetext{
6 The plot we provide in Fig. 1 is for the unrotated factor loadings. The curvilinear pattern also persists with varimax rotation.
} 
see also the proofs of Davison, 1977; Ross and Cliff, 1964), one way that it is sure to manifest is through the application of factor analysis to data that conform to the Coombsian unfolding model (1964). The fundamental problem is that factor analysis "assumes that values of the observed variables are linearly (or even monotonically) related to the values on the underlying latent variables; however, in an unfoldable dataset, values of the observed variables are quadratically (or at least single-peakedly) related to values on the latent variables" (Van Schuur and Kiers, 1994, p. 97). In general, this problem will lead factor analyses to produce at least one more factor than is actually present in the data structure. If the input data are $k$-dimensional, then factor analysis always returns at least $k+1$ factors. If the input data are one-dimensional, then factor analysis returns the "horseshoe".

Finally, note in Fig. 1 that the correct ordering of the voters occurs in the second factor, while the curvature of the horseshore (the "extra" factor) occurs in the first! As Van Schuur and Kiers (1994) point out, the "magnitude of the additional factor's eigenvalue depends on the distribution of persons and stimuli along the latent dimension. Sometimes the eigenvalue

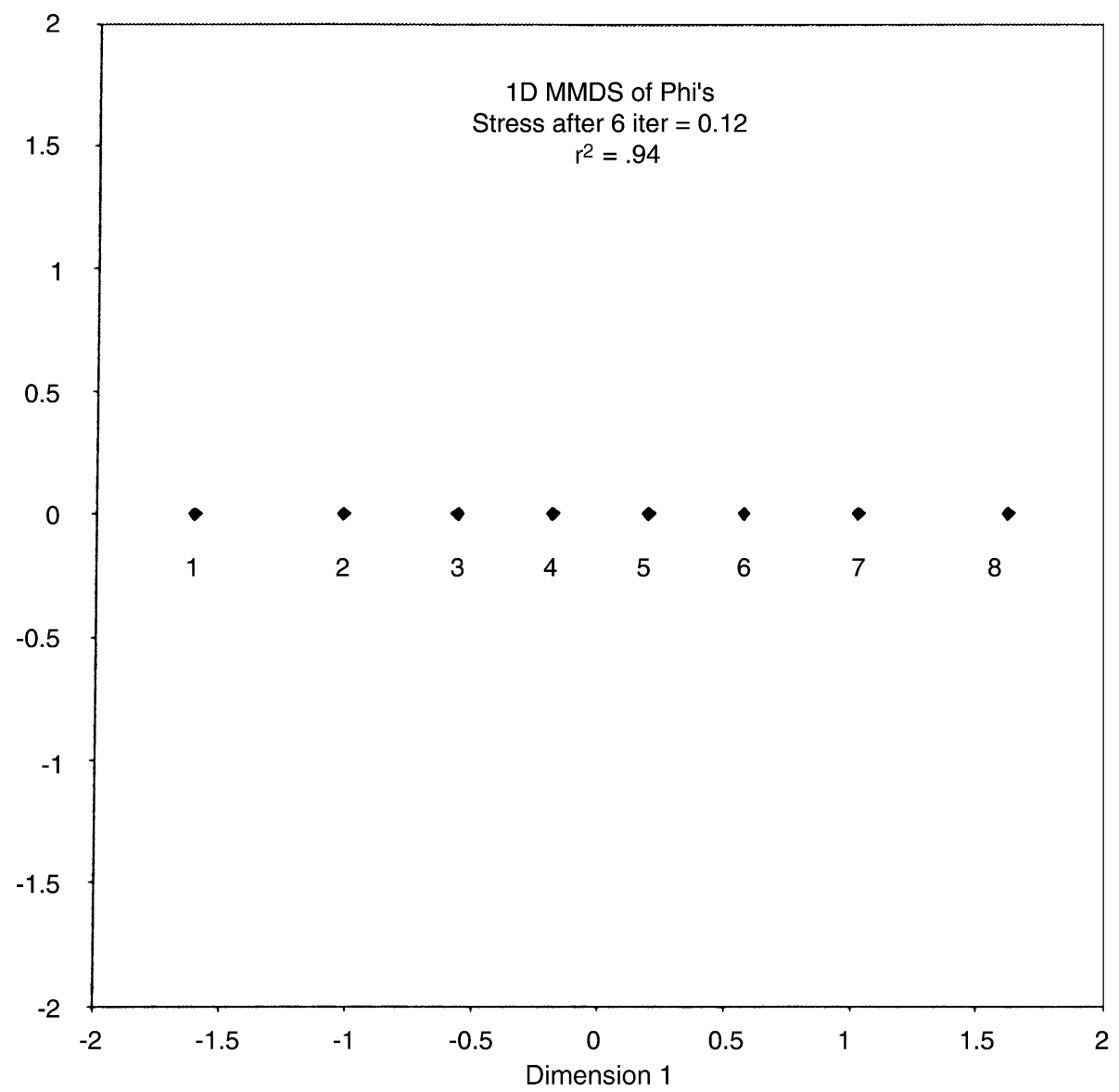

Fig. 2. One-dimensional metric MDS (MMDS) of phi coefficients. 
of the extra factor is even higher than the eigenvalue(s) of the other factor(s)" (p. 101). Thus, the inclusion of the extra factor is doubly dangerous; it may not even be the last of your potential factors.

Let us now turn to an alternative approach to scaling these voting records. If we submit the same $8 \times 8$, voter by voter matrix of correlation coefficients to one-dimensional MMDS we get the results displayed in Fig. 2. The stress (Kruskal stress form 1) of the final configuration is a respectable 0.12 , and the $r^{2}$ between the input similarities and the interpoint distances in the figure is 0.94 , a remarkably nice fit. However, note that the distance between extreme end points and those adjacent is greater than that between interior points, while no such relative inter-voter differences are apparent in the data structure itself. This is an indication of a potential problem.

That problem becomes apparent if we instead ask for a two-dimensional MMDS solution of the same input matrix. The result appears in Fig. 3. As you can see, the horseshoe is back (indicating that factor analysis is not the only scaling method susceptible to the problem,

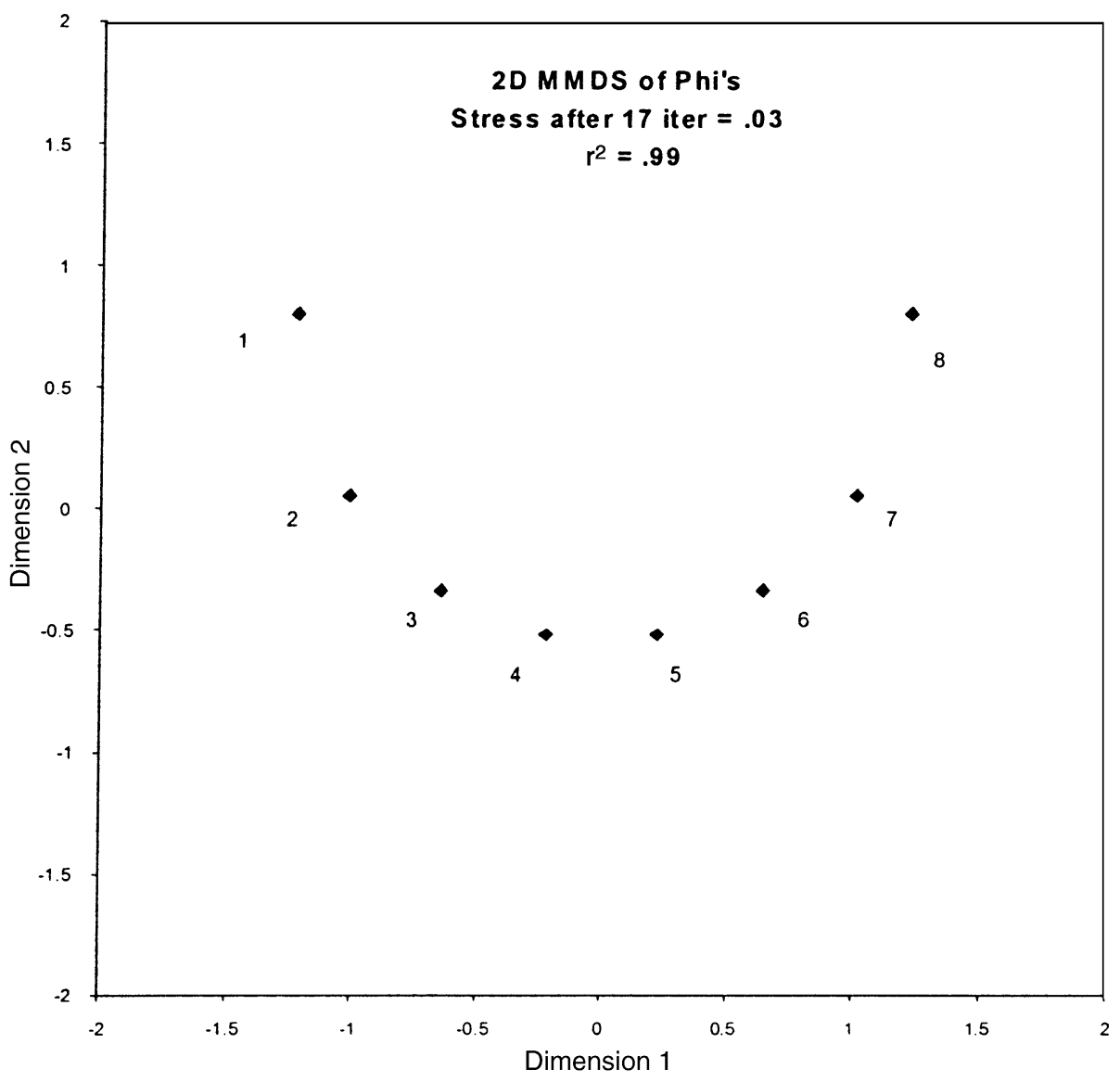

Fig. 3. Two-dimensional MMDS of phi coefficients. 
see Kruskal and Wish, 1978), though at least the first dimension does correspond to the underlying ideological dimension and the artifactual curvature occurs in the second, unlike in our factor analysis above. But the fit (as measured by stress and $r^{2}$ ) is better than the onedimensional solution, apparently indicating that the two-dimensional solution is preferable.

What MDS attempts to account for, both in the unequal spacing of the points in Fig. 2 and with the horseshoe in Fig. 3, are the effects of using the phi coefficient to measure the similarity of voting profiles. The phi coefficient is a Chi-square-based measure, and thus, in effect takes account of the column totals of the voters to be compared. This produces phi coefficients that vary not only with the number of agreements or disagreements between pairs of voters, but also with the relative positions of the voters involved. For example, when the voters are both from the same extreme end of the ideological continuum their voting records will both be mostly all 1's or all 0's, and a one vote disagreement will be given relatively more weight (depressing the phi coefficient), than if the voters are more centrist with roughly equal numbers of 1's and 0's in their records. Thus, phi between voters 1 and

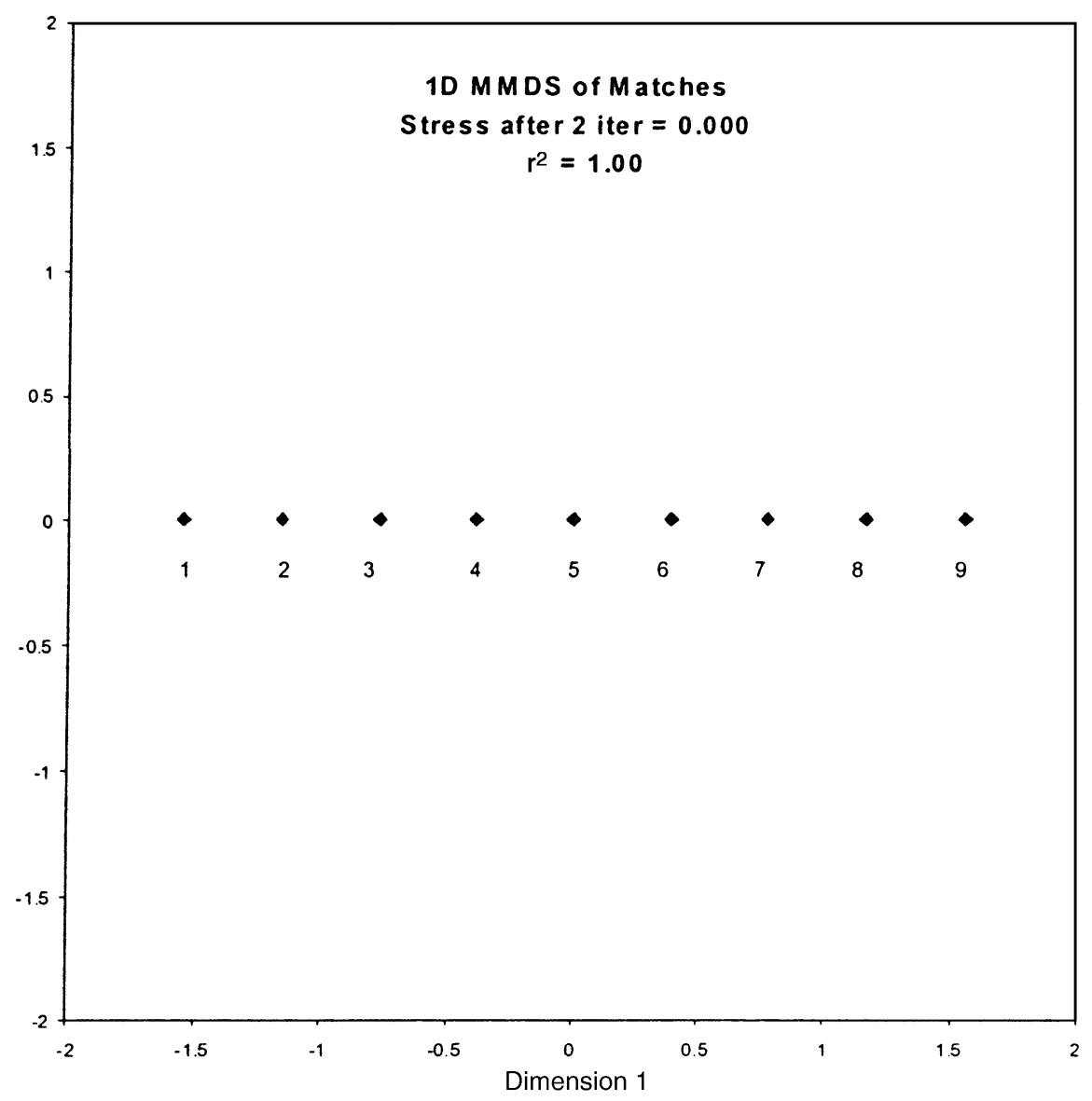

Fig. 4. One-dimensional MMDS of matching coefficients. 
2 equals 0.66 , while phi between voters 4 and 5 equals 0.80 , even though there is only a one-vote disagreement in each case (see Table 1).

To avoid these disparities we have chosen to use a simple proportion of exact matches coefficient rather than the phi coefficient to assess inter-voter similarity. Using this measure of similarity, we can now include our ninth voter in our analyses. We submitted the $9 \times 9$ matrix of matching coefficients to one-dimensional MMDS, and the result is Fig. 4. Note that the fit of this one-dimensional solution is now perfect ( stress $=0.0, r^{2}=1.00$ ). Further, our choice of similarity coefficient has eliminated the unequal spacing that was evident in Fig. 2.

Moreover, if we submit this matrix of matching coefficients to a two-dimensional MMDS, not only do we not get the horseshoe shape, but the stress is marginally worse than the one-dimensional solution and it took a much larger number of iterations to achieve it (see Fig. 5). Finally, the use of the matching coefficients for a form of exploratory principal components factor analysis partially alleviates the curvature of the horseshoe effect and increases the explanatory power of the factors. But this effect is minor; the results still seem

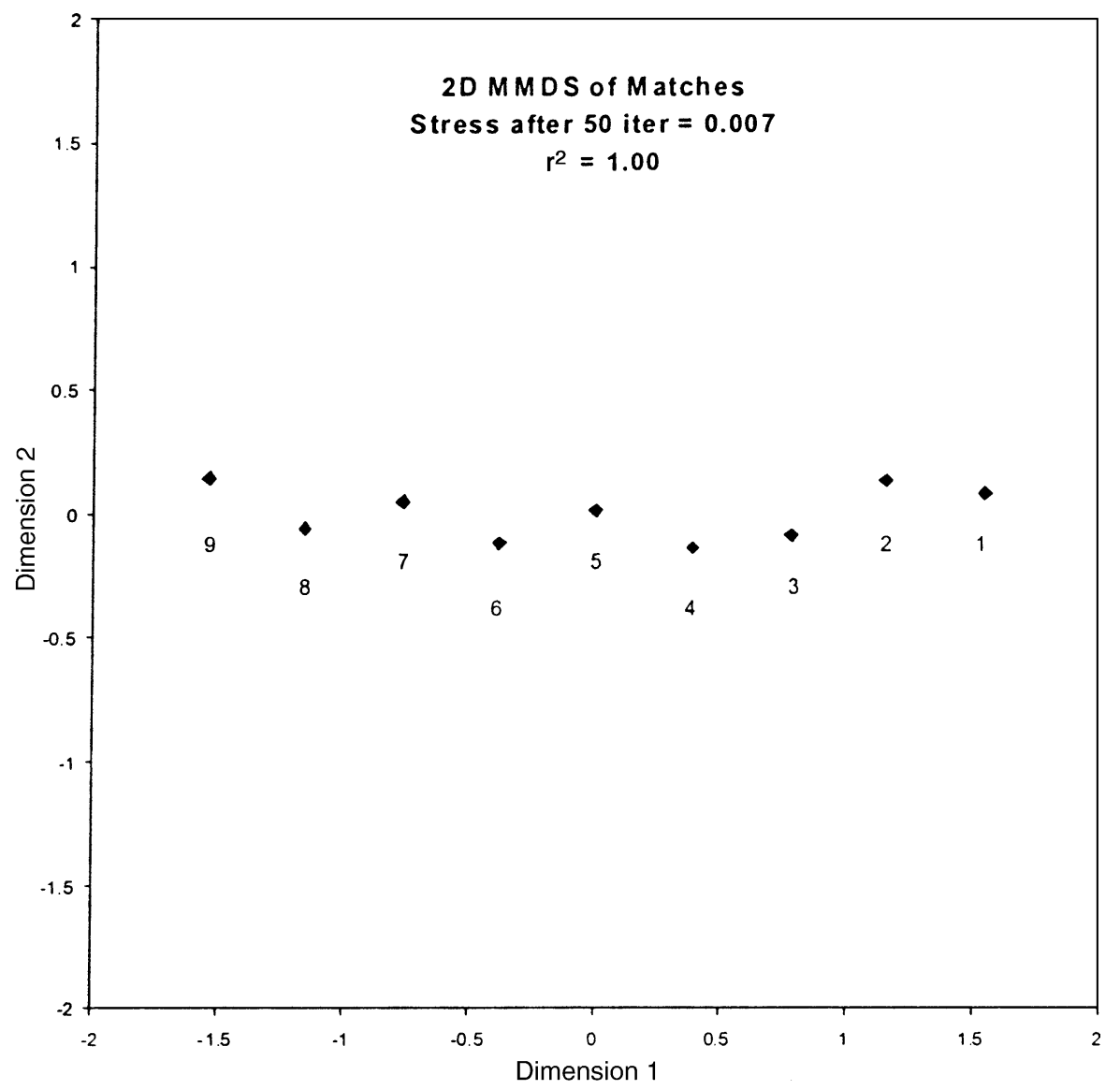

Fig. 5. Two-dimensional MMDS of matching coefficients. 


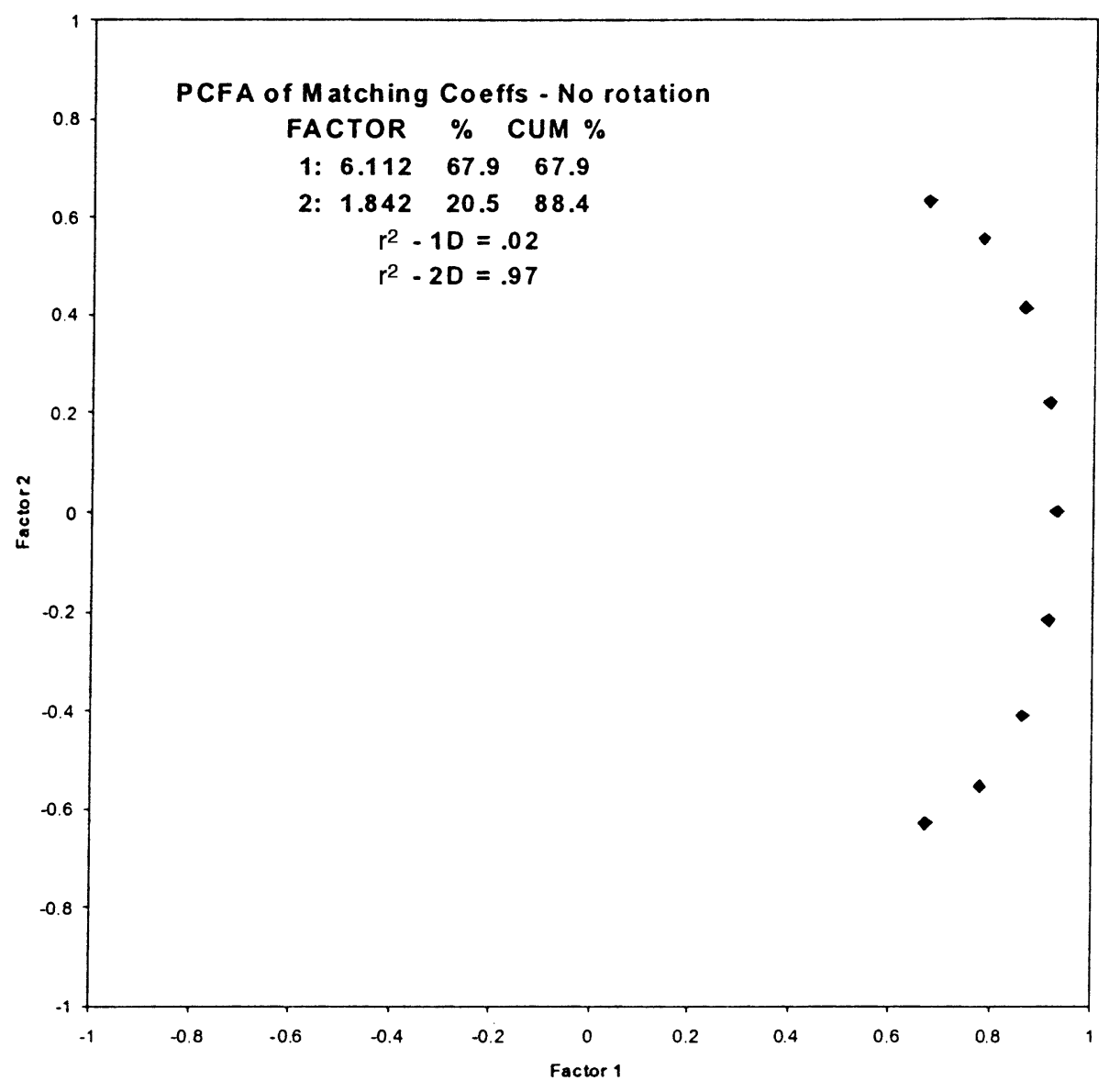

Fig. 6. Principal components factor analysis of matching coefficients-no rotation.

to indicate that two factors are necessary, and the eigenvalue of the extra factor is still larger than that for the factor corresponding to ideological position (see Fig. 6).

While space does not permit a full discussion here, it is worth mentioning other aspects of this sort of data that may affect the results of factor analyses. Among these, we have found evidence that both the number and the distribution of unique voting patterns along a single dimension can drastically affect the estimates of dimensionality provided by factor analysis.

\section{Comparisons of simulations in one- and two-dimensions with error variance}

In this section, we wish to compare the results of the application of factor analysis and MDS to both one- and two-dimensional binary choice roll-call data, under conditions closer to what one might actually find in the voting record of the Supreme Court. We allow for the 
possibility of error in the decision process, and we vary the number of votes in which any one panel of voters participates.

To simulate two-dimensional data we first select at random nine points from a uniform distribution over a unit square. To generate a binary choice vote from such a two-dimensional array, we draw an additional two points from the same unit square at random then conduct a vote between them. Here, all voters on one side of the perpendicular bisector line between the two points prefer one alternative and all voters on the other side of the perpendicular bisector prefer the other points (voters having voter ideal points on the perpendicular bisector line are indifferent-ties are a trivial complication we will not bother with).

To add error to the voting record, a small random normal deviate from a distribution with a specified standard deviation was added to each voter's estimations of the distance between his/her ideal point and each of the two alternatives in each vote. In addition to a no-error condition, two other levels of error were considered initially with standard deviations of 0.05 , and 0.10 .

Finally, we examined situations where each panel of voters participated in 50, 200, or 500 votes. These levels were chosen to approximate the range of the number of cases heard (votes) by the sessions of the US Supreme Court we will be examining shortly.

We generated 10 sets of roll-call votes for each combination of dimensionality, error level, and number of votes. We then submitted each set of votes to the standard principal components factor analysis (based on the matrix of phi coefficients, no rotation) and to MMDS (based on the simple matching coefficients) with one-, two-, three-, four-, and five-dimensional solutions.

The first result to note is that varying the number of votes had only a very minor impact on the fit and dimensionality of both the factor analyses and the MDS solutions. For example, in the case of the one-dimensional simulated data, the variance accounted for by the first factor for the 50-vote condition, averaging across the three initial error levels, is $44.1 \%$, while for the 200 -vote condition it is $40.0 \%$, and for the 500 -vote condition it is $39.3 \%$. The cumulative variance accounted for by two-factor solutions, again averaging over error levels, was $65.2 \%$ for the 50 -vote condition, $60.6 \%$ for the 200 -vote condition, and $59.3 \%$ for the 500-vote condition. We also examined the cumulative variance accounted for by three, four and five-factor solutions, and saw the same relatively small differences across numbers of votes. On average, increasing the votes 10-fold (from 50 to 500) decreases the variance accounted for by solutions with a given number of factors by only $5.7 \%$.

Interestingly, the number of votes makes even less difference when factor analyzing the two-dimensional simulated data. In this case, the variance accounted for by the first factor for the 50-vote condition, averaging across the three initial error levels, is $43.0 \%$, while for the 200 -vote condition it is $41.2 \%$, and for the 500 -vote condition it is $40.3 \%$. The cumulative variance accounted for by two-factor solutions, again averaging over error levels, was $67.2 \%$ for the 50 -vote condition, $65.7 \%$ for the 200 -vote condition, and $65.4 \%$ for the 500-vote condition. Again, a similar pattern pertains as we examine the cumulative variance accounted for by three, four and five-factor solutions. On average, increasing the votes 10-fold (from 50 to 500) decreased the variance accounted for by solutions with a given number of factors by only $1.8 \%$.

Likewise, the only noticeable difference in the MDS results across the numberof-votes conditions appears in the $r^{2}$ fit of the one-dimensional solutions for the 
two-dimensional data. On average these $r^{2}$ values are about $5 \%$ higher in the 50 -vote condition than in the 200-vote condition, but the difference is negligible between the 200- and 500 -vote conditions. Given these findings and those above, only the results for the 200-vote condition are included below to conserve space.

Secondly, we noted that there was very little degradation in the fit of either the factor analyses or MDS solutions over the initial error rates we had generated. Thus, we ran additional simulations in the 200 -vote condition with random normal deviates drawn from distributions with standard deviations of 0.30 and 0.40 . To illustrate the effect of the full range of error variation we simulated, we include below results from three error levels; no error, 0.10, and 0.40. Figs. 7 and 8 show these results.

Fig. 7 is a collection of scree plots (Cattell, 1965), where each point represents the average eigenvalue (of the specified factor) for the 10 sets of roll-call votes for the indicated error level and true dimensionality. At first glance, there seems to be very little difference between eigenvalues of the one and two-dimensional data. The average size of the first eigenvalue, for instance, is approximately the same within a given error level. Both types of data seem to require at least three factors by the Kaiser (1974) criterion; that is, they seem to have at least three eigenvalues greater than or equal to one. Secondly, the error level seems to have had two effects. First, as the error level increases, there is a reduction in the magnitude of the first eigenvalue (as we might expect), but there is also a slight (but odd) improvement in the degree to which the factor analyses distinguish between the one and two-dimensional data. At the 0.10 error rate, there is a tendency for the average eigenvalues of the one-dimensional data to "elbow" after the second factor (indicating a preference for the two factor representation, see Kim and Mueller, 1978, pp. 44-45) and for the two-dimensional data to "elbow" after the third factor (indicating a three factor representation). With the general reduction overall in size of the eigenvalues for the 0.40 error rate, the elbowing seems less pronounced, but with only 10 sample data sets in each case, it is hard to say that this is a clear pattern. Nevertheless, it is probably fair to say that anyone examining these eigenvalues in the usual way would not reach the correct conclusions about the dimensionality of the data. This is true for the cumulative percentage of variance explained by the factors too. In the no error condition, the first factor for the one-dimensional data explained $42 \%$ of the variance on average, while for the two-dimensional data, the first factor explained $46 \%$. After five factors, factor analysis explained $92 \%$ of the variance in the one-dimensional data and $93 \%$ of the two-dimensional data. In the 0.10 error condition, the first factor for the one-dimensional data explained $36 \%$ of the variance on average, while for the two-dimensional data, the first factor explained $37 \%$. After five factors, factor analysis explained $82 \%$ of the variance in the one-dimensional data and $85 \%$ of the two-dimensional data. Finally, in the 0.40 error condition, the first factor for the one-dimensional data explained $23 \%$ of the variance on average, while for the two-dimensional data, the first factor explained $20 \%$. After five factors, factor analysis explained only $68 \%$ of the variance in both the one-dimensional data and in the two-dimensional data.

Fig. 8, however, seems to paint a more accurate picture. It presents the results for the MMDS solutions. Each point represents the average $r^{2}$ value (between the input matching coefficients and the recovered distances from the specified $n$-dimensional solution) of the 10 sets of roll-call votes for the indicated error level and true dimensionality. The most obvious result is that MMDS clearly distinguishes one-dimensional data from two-dimensional data 

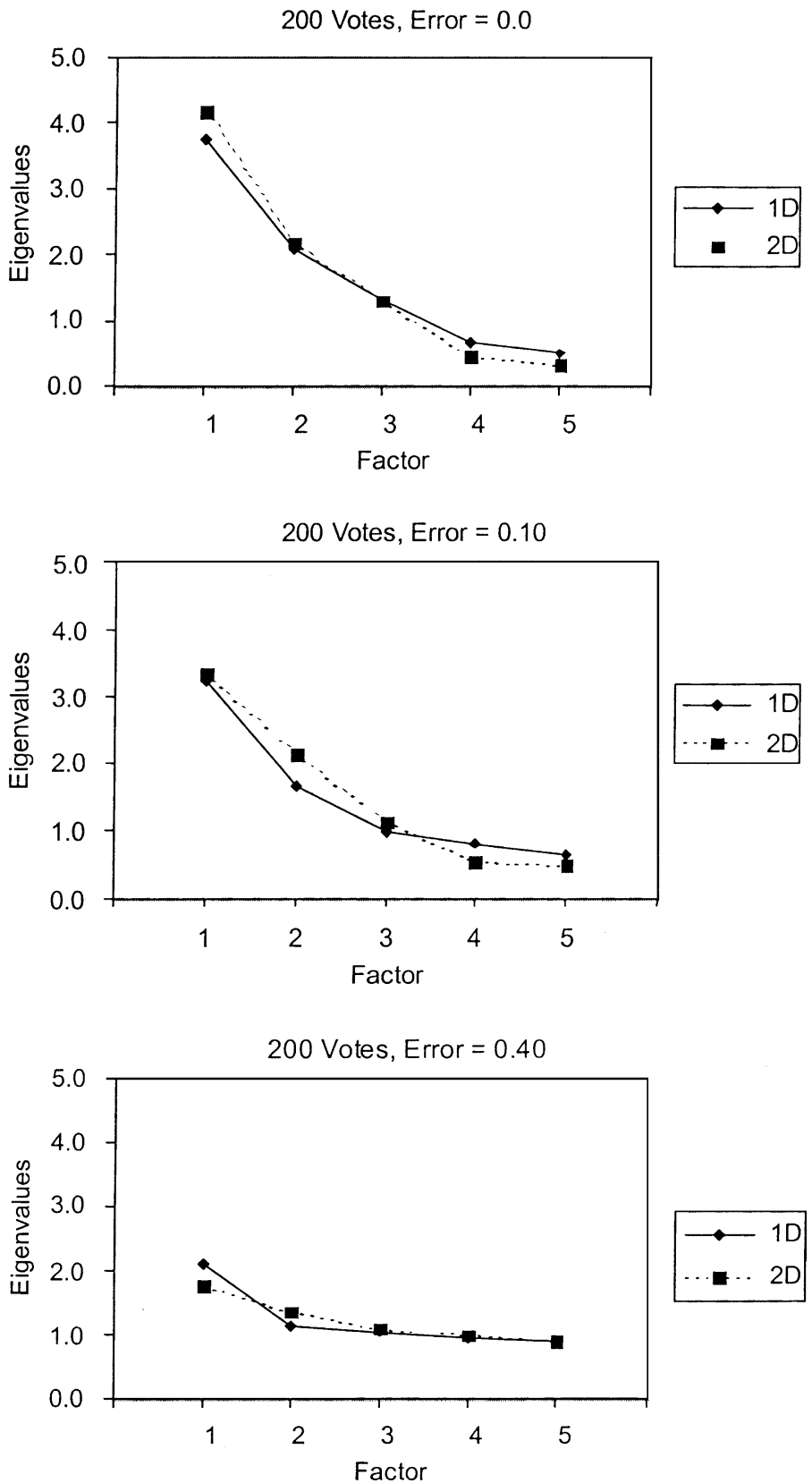

Fig. 7. Scree plots of average eigenvalues from principal components factor analysis of one- and two-dimensional data under various error conditions. 

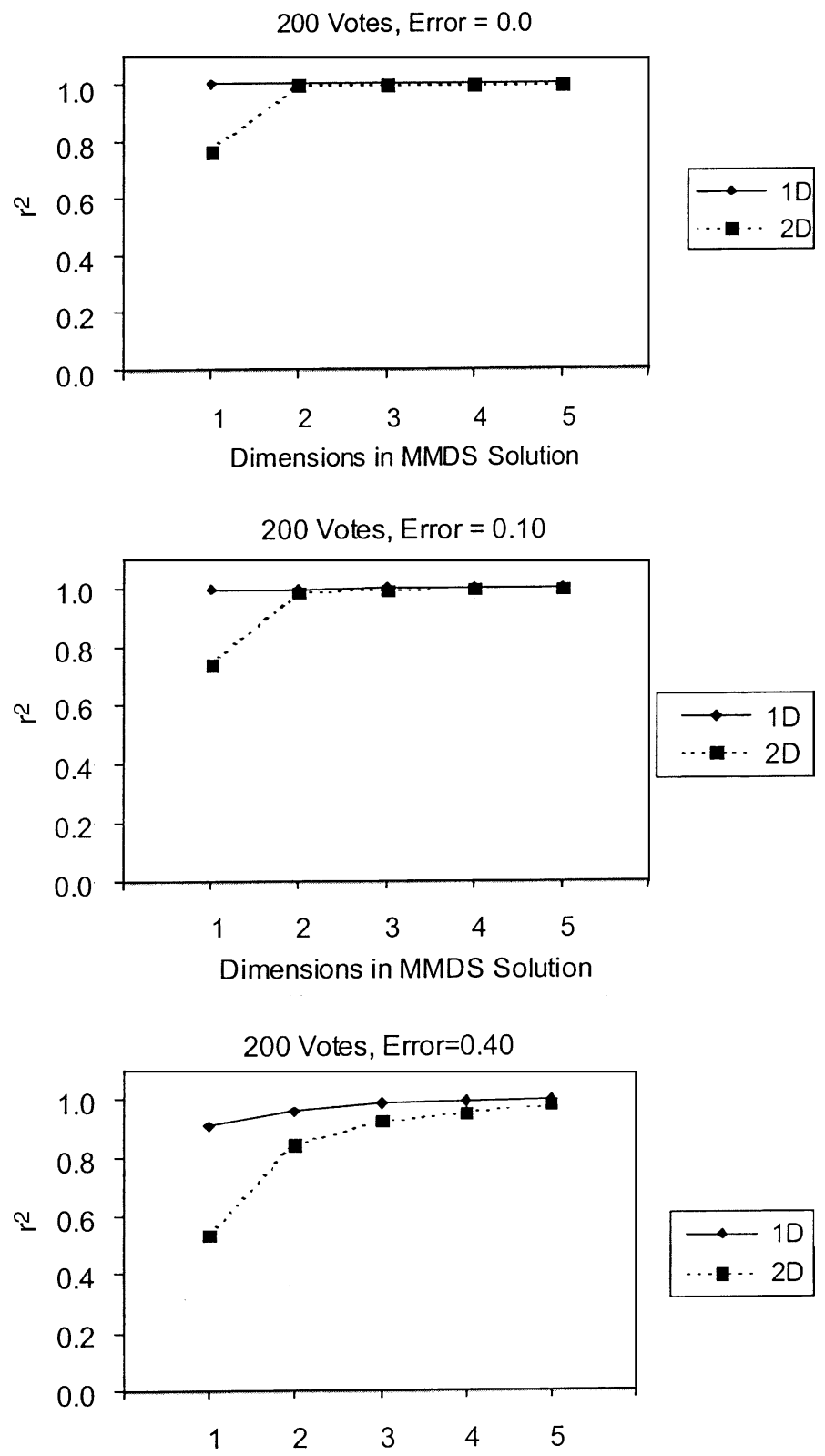

Dimensions in MMDS Solution

Fig. 8. Plots of $r^{2}$ 's assessing fit of MMDS solutions in several dimensionalities for one- and two-dimensional data under various error conditions. 
under these circumstances, and correctly specifies the true dimensionality. The fit of truly one-dimensional data is perfect or nearly perfect in the one-dimensional solutions. Even at the highest error level, the average $r^{2}$ is 0.91 . The one-dimensional solutions for the two-dimensional data, however, achieve $r^{2}$ values of only $0.76,0.74$ and 0.53 across error levels, while the two-dimensional solutions of the same data achieve $r^{2}$ values much closer to $1.00(0.99,0.97$, and 0.82 for the three error levels, respectively). These two-dimensional MDS results, however, may be misleading in isolation too, as MDS misallocates about $70 \%$ of the variance to the first dimension (at the lower error rates, at least) when in reality the variance should be approximately equally split between the first two-dimensions. Thus, caution is necessary in its use as well, and comparisons to simulated data are critical.

Nonetheless, it seems that MMDS provides much greater ability to determine the true underlying dimensionality of unfoldable data than does principal components factor analysis. In the next section we will apply the benchmarks we have established in this section to data from the voting record of the US Supreme Court.

\section{Comparisons of scaling techniques for votes in the Supreme Court}

We draw our data from the voluminous and meticulous data base on Supreme Court decisions compiled by Spaeth (1993). For our analyses, we group the data by "natural courts", i.e. courts with the same panel of members. There were 23 natural courts under Chief Justices Warren, Burger, and Rehnquist during the period 1953-1991 covered by Spaeth's dataset. Of these, we first selected the 17 courts with nine members, to ensure both maximum comparability and to avoid the bias towards smaller dimensionality that a smaller number of justices might produce. We also analyze only those cases from this data set uniquely identified by case citation number, in which the Court heard oral argument and gave a formally decided full opinion. While relatively rare, such cases are the precedent setting decisions that attract the most attention from legal and Court scholars.

Spaeth's categorizations of justice's voting behavior were binarized by recoding "voted with majority", "regular concurrence", "special concurrence", and "judgment of the court" as concurrences and "dissent" as dissent. Cases where one or more justice's votes were categorized as "jurisdictional dissent", "dissent from a denial or dismissal of cert.", and "non-participation", (namely, those for which full roll-call data is not available) were also deleted from the data set. These coding choices led us to omit two more natural courts whose number of remaining cases was too small for reliable analysis in our opinion. We omitted the 4th Warren Court, which had only 26 valid cases for analysis after recoding, and the 7 th Warren Court, which had no valid cases after recoding. The minimum number of cases in any of the natural courts we analyze is 48 , in the 1 st Warren court. Though this leaves us with only 15 of the 23 natural courts from the 1953-1991 period, these courts (and our final data set) include 3363 of the total 3555 (94.6\%) orally argued, formally decided cases where the full roll-call vote is available. (For more detail on the nature of our data selection and Spaeth's data base, see Grofman and Brazill, in press).

Given these 15 sets of binary choice roll-call votes from the US Supreme Court, we may now proceed to a comparison of factor analysis and MDS free from the artificiality of simulated data. We treated these data in the same manner as that in the section above, as 
Table 2

Principal components factor analysis (unrotated) results

\begin{tabular}{|c|c|c|c|c|c|c|}
\hline \multirow[t]{2}{*}{ Court } & \multirow[t]{2}{*}{ \#Cases } & \multicolumn{5}{|c|}{ Eigenvalues (latent factor roots) } \\
\hline & & 1 & 2 & 3 & 4 & 5 \\
\hline Warren 1 & 48 & 2.36 & 1.88 & 1.44 & 1.14 & 0.86 \\
\hline Warren 3 & 75 & 3.27 & 1.84 & 1.52 & 0.87 & 0.46 \\
\hline Warren 5 & 116 & 3.86 & 1.49 & 1.17 & 0.78 & 0.50 \\
\hline Warren 6 & 291 & 3.61 & 1.68 & 1.00 & 0.69 & 0.61 \\
\hline Warren 8 & 270 & 2.44 & 1.80 & 1.11 & 0.98 & 0.73 \\
\hline Warren 9 & 161 & 2.89 & 1.88 & 1.18 & 0.81 & 0.72 \\
\hline Warren 10 & 98 & 1.87 & 1.58 & 1.35 & 1.12 & 0.91 \\
\hline Burger 2 & 95 & 2.96 & 1.98 & 1.24 & 0.93 & 0.78 \\
\hline Burger 4 & 394 & 3.03 & 1.69 & 1.27 & 0.84 & 0.64 \\
\hline Burger 6 & 569 & 2.58 & 1.53 & 1.26 & 0.91 & 0.86 \\
\hline Burger 7 & 624 & 3.01 & 1.93 & 1.03 & 0.82 & 0.68 \\
\hline Rehnquist 1 & 132 & 3.81 & 1.56 & 1.01 & 0.73 & 0.67 \\
\hline Rehnquist 3 & 303 & 3.53 & 1.95 & 1.02 & 0.68 & 0.62 \\
\hline Rehnquist 4 & 100 & 3.01 & 1.91 & 1.21 & 0.91 & 0.53 \\
\hline Rehnquist 5 & 87 & 2.48 & 1.75 & 1.26 & 1.19 & 0.87 \\
\hline Mean & & 2.98 & 1.76 & 1.20 & 0.89 & 0.70 \\
\hline S.D. & & 0.57 & 0.17 & 0.16 & 0.16 & 0.14 \\
\hline
\end{tabular}

they are commonly employed. We submitted them first to standard principal components factor analysis (based on the phi coefficients) and then to MMDS (based on the matching coefficients).

Let us turn first to an examination of the factor analysis results in Table 2, which contains the eigenvalues for the first five factors (unrotated) for each of the 15 natural courts, and Fig. 9, which contains the associated scree plots. As was the case for the simulated data above, using the usual criteria factor analysis would seem to indicate that the user should retain at least three factors for further analysis. The first three factors for all 15 courts have eigenvalues greater than one (again, see Kaiser, 1974), and three of the courts have four eigenvalues $>1$. In addition we note that the magnitude of the eigenvalues of the first (and possibly the second) factors are on average slightly lower than those produced by our simulations at the lower error rates (see Fig. 7), falling somewhere between the simulated results with error level 0.10 and 0.40 (though there is a great deal of variability among the Warren and Rehnquist courts). However, knowing what we might expect from the simulated data (comparing the scree plots in Figs. 7 and 9), we might tentatively conclude that these results likely arise from one or two-dimensional data.

Table 3 contains values for the proportion of variance in the correlation matrix explained by each eigenvalue for each of the 15 courts. Here again, based on this commonly employed criterion (Kim and Mueller, 1978), one might conclude that a rather large number of factors (and thus underlying dimensions) are necessary to explain the patterning of the votes of the Supreme Court. Note that after the first five factors, the average cumulative percentage of variance explained is just $83.72 \%$. In reference to the simulations, however, these results do not seem much different from the one or two-dimensional data with error levels equal to 0.10 . 

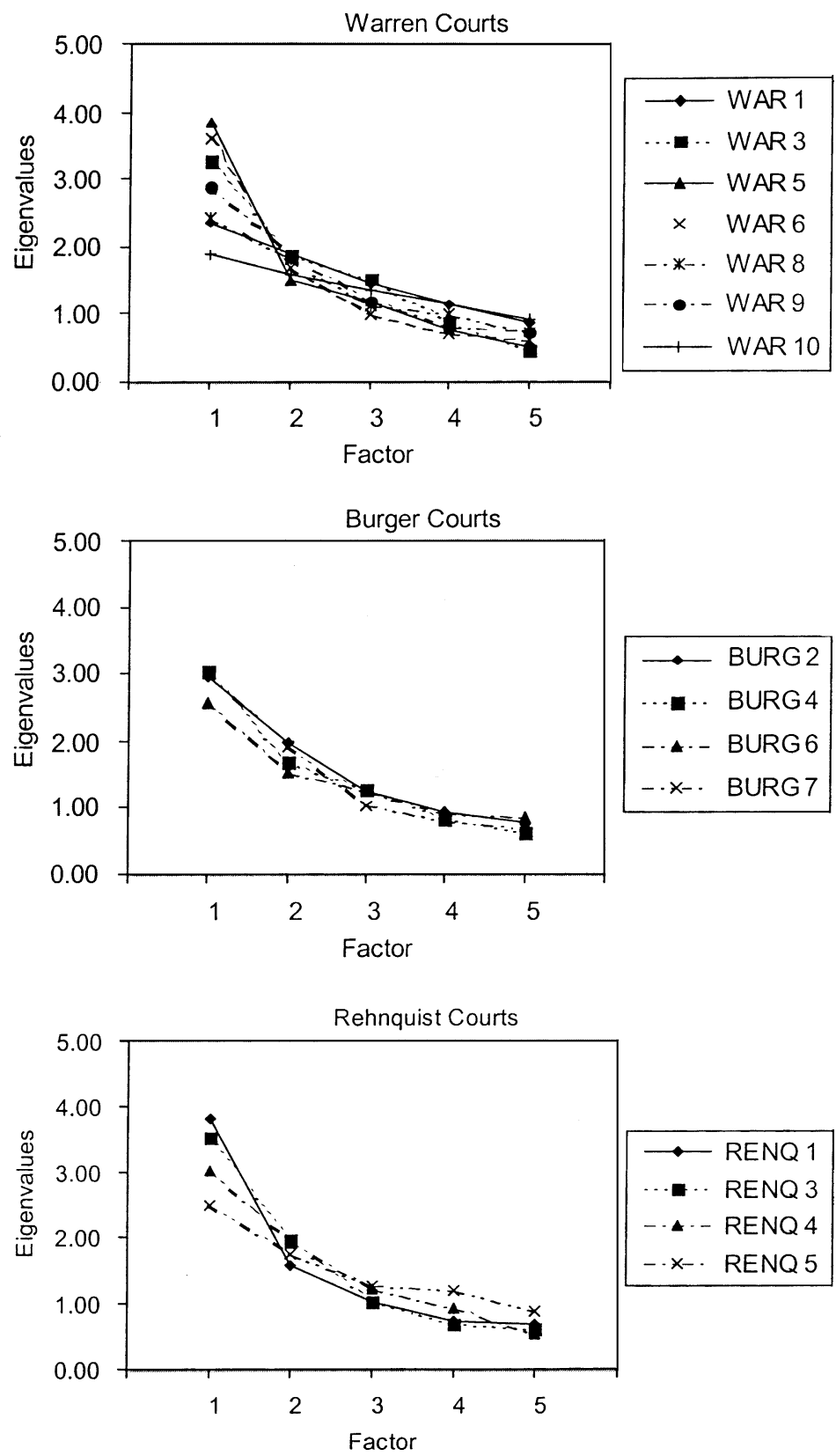

Fig. 9. Scree plots of eigenvalues from principal components factor analysis of Natural Courts under Chief Justices Warren, Burger and Rehnquist. 
Table 3

Principal components factor analysis (unrotated) results

\begin{tabular}{lclllll}
\hline Court & \#Cases & \multicolumn{5}{l}{ Cumulative proportion of variance explained by each eigenvalue (latent factor root) } \\
\cline { 3 - 7 } & & 1 & 2 & 3 & 4 & 5 \\
\hline Warren 1 & 48 & 0.26 & 0.47 & 0.63 & 0.76 & 0.85 \\
Warren 3 & 75 & 0.36 & 0.57 & 0.74 & 0.83 & 0.88 \\
Warren 5 & 116 & 0.43 & 0.59 & 0.72 & 0.81 & 0.87 \\
Warren 6 & 291 & 0.40 & 0.59 & 0.70 & 0.78 & 0.84 \\
Warren 8 & 270 & 0.27 & 0.47 & 0.59 & 0.70 & 0.78 \\
Warren 9 & 161 & 0.32 & 0.53 & 0.66 & 0.75 & 0.83 \\
Warren 10 & 98 & 0.21 & 0.38 & 0.53 & 0.66 & 0.76 \\
Burger 2 & 95 & 0.33 & 0.55 & 0.69 & 0.79 & 0.88 \\
Burger 4 & 394 & 0.34 & 0.52 & 0.67 & 0.76 & 0.83 \\
Burger 6 & 569 & 0.29 & 0.46 & 0.60 & 0.70 & 0.79 \\
Burger 7 & 624 & 0.33 & 0.55 & 0.66 & 0.75 & 0.83 \\
Rehnquist 1 & 132 & 0.42 & 0.60 & 0.71 & 0.79 & 0.86 \\
Rehnquist 3 & 303 & 0.39 & 0.61 & 0.72 & 0.80 & 0.86 \\
Rehnquist 4 & 100 & 0.33 & 0.55 & 0.68 & 0.78 & 0.84 \\
Rehnquist 5 & 87 & 0.28 & 0.47 & 0.61 & 0.74 & 0.84 \\
Mean & & 0.33 & 0.53 & 0.66 & 0.76 & 0.84 \\
S.D. & & 0.06 & 0.06 & 0.06 & 0.05 & 0.04 \\
\hline
\end{tabular}

Now, if we instead analyze these data with MMDS, what conclusions might we reach? Table 4 contains the $r^{2}$ values between the input matching coefficients and the pairwise interpoint distances from one-, two- and three-dimensional MMDS solutions for each of the 15 natural courts, and Fig. 10 shows the same data in graphical form. First note that the

Table 4

Metric MDS results for 15 natural courts, values represent $r^{2}$ between recovered distances and input matching coefficients

\begin{tabular}{lclll}
\hline Court & \#Cases & $\begin{array}{l}\text { One-dimensional } \\
\text { solution }\end{array}$ & $\begin{array}{l}\text { Two-dimensional } \\
\text { solution }\end{array}$ & $\begin{array}{l}\text { Three-dimensional } \\
\text { solution }\end{array}$ \\
\hline Warren 1 & 48 & 0.7 & 0.91 & 0.98 \\
Warren 3 & 75 & 0.63 & 0.98 & 0.99 \\
Warren 5 & 116 & 0.94 & 0.98 & 0.99 \\
Warren 6 & 291 & 0.95 & 0.99 & 0.99 \\
Warren 8 & 270 & 0.92 & 0.98 & 0.99 \\
Warren 9 & 161 & 0.77 & 0.99 & 0.99 \\
Warren 10 & 98 & 0.71 & 0.97 & 0.99 \\
Burger 2 & 95 & 0.82 & 0.96 & 0.99 \\
Burger 4 & 394 & 0.96 & 0.99 & 0.99 \\
Burger 6 & 569 & 0.84 & 0.95 & 0.98 \\
Burger 7 & 624 & 0.91 & 0.99 & 0.99 \\
Rehnquist 1 & 132 & 0.94 & 0.98 & 0.99 \\
Rehnquist 3 & 303 & 0.96 & 0.99 & 0.99 \\
Rehnquist 4 & 100 & 0.96 & 0.98 & 0.99 \\
Rehnquist 5 & 87 & 0.85 & 0.94 & 0.95 \\
Mean & & 0.86 & 0.97 & 0.99 \\
S.D. & & 0.11 & 0.02 & 0.01 \\
\hline
\end{tabular}




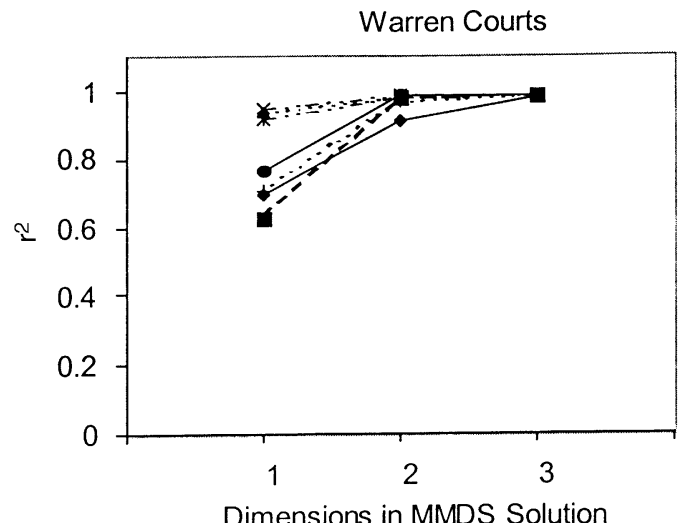

$$
\begin{aligned}
& \longrightarrow \bullet \text { WAR } 1 \\
& --- \text { WAR } 3 \\
& \cdots \cdots \text { WAR } 5 \\
& -\times- \text { WAR } 6 \\
& -\cdots-\text { WAR } 8 \\
& - \text { WAR } 9 \\
& \cdots+\cdots \text { WAR } 10
\end{aligned}
$$

Dimensions in MMDS Solution

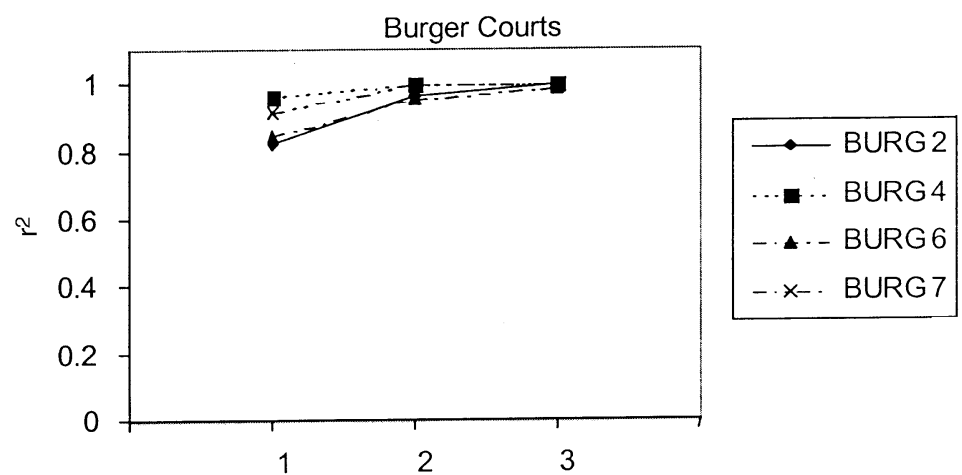

Dimensions in MMDS Solution

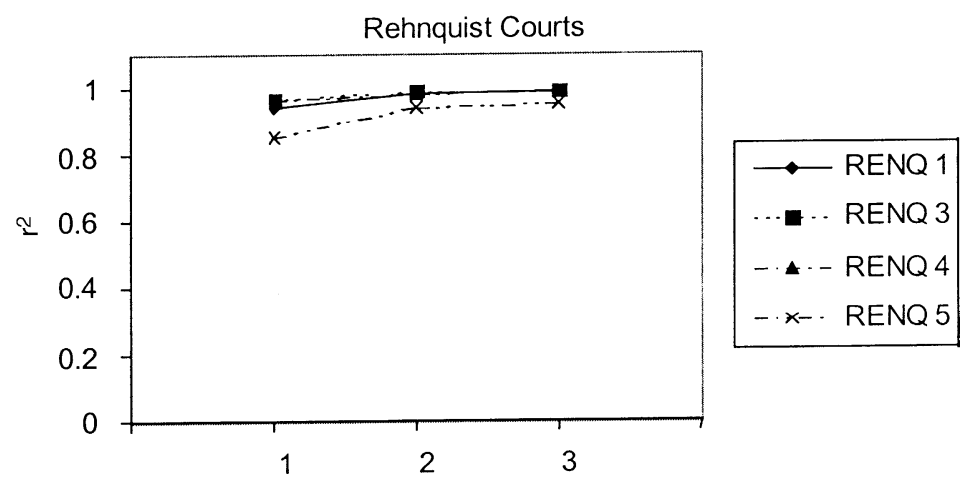

Dimensions in MMDS Solution

Fig. 10. Plots of multiple $r^{2}$,s assessing fit of MMDS solutions in several dimensionalities of Natural Courts under Chief Justices Warren, Burger and Relinquist. 
mean $r^{2}$ for the one-dimensional solutions is 0.86 , and two-dimensions seem to explain nearly all of the variance (including error) for the majority of the courts. In comparison with the results in Fig. 8, we note that the one-dimensional fit of the court data is not as good as that of the simulated one-dimensional data with low error ( $r^{2}$,s near 1.00), but it seems substantially better than the one-dimensional fit of the simulated two-dimensional data $\left(r^{2}\right.$, $\mathrm{s}$ near 0.70 , even without error). Indeed, only 4 of the 15 courts (Warren 1, 3, 9, and 10) display patterns of $r^{2}$ 's that resemble the simulated two-dimensional data. Without these, the mean one-dimensional fit of the other 11 courts rises to a remarkable 0.91 . It seems possible that for these courts the remaining variance may be attributable to error (or idiosyncratic decisions on some few cases), given that this is the same average $r^{2}$ we achieved for the simulated one-dimensional data with error level 0.40 . It is perhaps also worth noting that the trend seems to be towards stronger evidence for unidimensionality as we move from the Warren courts (mean $r^{2}=0.80$ ) to the Burger courts (mean $r^{2}=0.88$ ) to the early Rehnquist courts (mean $r^{2}=0.93$ ). This seems to square well with the popular observation that during this period in the United States, American political behavior (and perhaps judicial behavior) became more polarized ideologically (Poole and Rosenthal, 1984). In any event, it seems clear that MMDS provides a more parsimonious description of the Supreme Court data than do the usual methods of principal components factor analysis. It also seems likely that the improved understanding gained by the use of the proper methodology will help clarify a number of lingering debates in political science and sociology surrounding this type of data. We discuss some of these points below.

\section{Discussion}

Our findings are quite clear: for binary choice voting data (such as yes/no votes by a set of legislators on some set of bills, or reverse/affirm votes by members of a multi-judge appellate court on some set of cases on appeal before it) the results we get from factor analysis are fundamentally misleading. While factor analyses can be improved slightly by substituting a pairwise matching coefficient for the standard correlations as input, this substitution only mitigates the problem. It does not eliminate it. In contrast, MDS performs with flying colors in recreating the dimensionality of binary choice data, even when noise is introduced to the data.

(1) For data that is one-dimensional in nature, factor analysis finds at least one factor more than there really is (and often two more), and this becomes obvious in the two-dimensional representations as the well-known horseshoe artifact. In contrast, MDS accurately recreates a single dimension, given the use of an appropriate measure of similarity (namely, a pairwise matching coefficient).

(2) When we look at data that is two-dimensional in nature, our simulations find factor analysis again almost invariably finds at least one extra (third) factor, albeit with usually $>80 \%$ of the variance attributed to the first two factors. However, although MDS accurately finds only two-dimensions, it misallocates variance between them. While the two factors have equal explanatory power in the data, MDS allocates too much weight to the first factor (approximately 70\%). 
(3) We find that MDS is better able to discriminate between one-dimensional and twodimensional data than is factor analysis, even under error prone conditions.

(4) Our analysis of data from the US Supreme Court supports well the conclusions based on simulations above.

We are certainly not the first to describe these problems with factor analysis. Going back at least as far as Guttman (1958) and Coombs and Kao (1960), various specialists on scaling have observed that factor analyses of binary data which generates a perfect Guttman scale, or data that is generated by an unfolding model generally, will invariably overstate the number of dimensions. The graph of the first two-dimensions of the factor analysis will be U-shaped with the appearance of being bent inward (see e.g. Ross and Cliff, 1964; Davison, 1977; Van Schuur, 1984; Roberts and Laughlin, 1996). However, in political science and sociology, either these points have been overlooked or their implications for appropriate analyses have been completely misunderstood. Factor analysis continues to be used in contexts in which it is simply inappropriate, and scholars often succeed in cleverly giving substantive interpretations to dimensions found in factor analytic studies, even though these dimensions are artifactual—much as Ptolemy succeeded in fitting a complex pattern of epicycles to show exactly how the sun moved around the earth, even though (as Galileo and Copernicus were to demonstrate) in actuality, it was the earth which moved around the sun.

In particular, our findings shed direct light on the controversy between Poole and Rosenthal (1984, 1991, 1997), on the one hand, and Clausen (1973) and Koford (1989, 1991), on the other, over the dimensionality of Congressional voting. Our results show that Koford is right that MDS methods may overweight the first dimension in an attitude structure, but that the MDS methodology used by Poole and Rosenthal nonetheless provides a quite accurate representation of the dimensionality of legislative choice. Our findings also show (like Van Schuur and Kiers, 1994) that results reporting two independent factors for what should be a single liberal-conservative dimension of party affiliation (e.g. Schubert, 1965; Weisberg, 1980) should be taken with several grains of salt; they are almost certainly artifacts of the factor analysis used to generate the dimensionality estimates.

There are still a number of questions that our analyses leave unanswered. For unidimensional data the perfect Guttman scale we expect from ideological preferences may also arise from differences in judgmental ability. Thus, we cannot use the raw data itself to distinguish whether the underlying voter choice process best reflects judgments or preferences. But what about data drawn from evaluations based on more than one-dimension or involving preferences among more than two alternatives? Is it possible to develop heuristics for such data that might allow us to distinguish whether the judgmental or the ideological model is a better fit? Also, how do we integrate real-world information beyond just pairwise preferences when we are trying to decide whether judgments or ideology provides the underpinnings of observed data patterns?

Secondly, do the results we give about the superiority of MDS over factor analysis continue to hold when we move beyond binary voting data, such as provided by roll-call votes to other more information-rich types of data, e.g. data that allows us to reconstruct the ordinal (or even cardinal) preferences of voters across a set of alternatives? For reasons of space limitations, in this essay we have dealt only with binary choice data. There are at least two other important types of voting/preference data for which comparisons of MDS and factor 
analysis should be made: (1) rank order data on voter preferences, such as provided by ballots for the Single Transferable Vote or the Alternative Vote (Taagepera and Shugart, 1989; Bowler and Grofman, 2000), or as can be reconstructed from Likert or (cardinal) thermometer scales (Neimi and Weisberg, 1974; Feld and Grofman, 1988, 1990; Regenwetter et al., 1999) on which respondents provide affective or cognitive evaluations of some set of parties, candidates, interest groups, etc. $;^{7}$ and (2) subset choice data, such as provided by ballots for elections conducted under approval voting (Brams and Fishburn, 1983; Regenwetter and Grofman, 1998a, 1998b).

Finally, we note that there are a number of other ways in which analysts might attempt to recover dimensional structure from the types of data we examine here. One of the oldest of these is Guttman scaling itself (Guttman, 1944, 1950a, 1950b). Bernard (1955), for instance, used Guttman scaling to search for meaningful orderings ('scales') of Justices of the US Supreme Court, based on voting patterns in several types of cases heard by the Court in 1951 and 1952. He scaled each type of case (e.g. constitutional cases, congressional statutes, etc.) separately, rather than taking the entire case roster as a whole as we did. While he found that most types of cases were scaleable, producing coefficients of reproducibility at or near the minimally accepted standard of 0.90 , the scales generated (i.e. the ordering of justices) did not agree across all of them. Bernard interpreted this as an indication of the lack of general unidimensionality (especially due to ideology) among the members of the Court.

Bernard, however, was using Guttman scaling in what Kronenfeld (1972) would call a "heuristic" (p. 257) manner, that is, shuffling and reshuffling the order of Justices and cases until a scale with an acceptable coefficient of reproducibility is found. Kronenfeld offers a number of caveats regarding its use in this manner. Drawing on Torgerson (1958) he points out that a high level of reproducibility may be "a necessary condition for a demonstration of unidimensionality, [but it] is far from sufficient to guarantee it" (p. 260). Minimally, Guttman scaling requires at least ten variables. In Bernard's case, these variables are justices, of which there are only nine. Further, each variable should have marginal frequencies of the modal response (concurrence or dissent, in this case) between 30 and 70 percent. This seems to be violated for several justices for several of the types of cases Bernard analyzes. Also, according to Torgerson and Kronenfeld, the pattern of errors in the Guttman pattern should be random. It is not clear that Bernard makes any attempt to assess this property for the scales he produces. Finally, though not discussed by Kronenfeld, it seems likely that there should be a lower bound on the number of cases observed before a scale may be deemed meaningful. Of the 20 sets of cases Bernard scaled, 10 had 8 or fewer cases. Ultimately, Kronenfeld argues that Guttman scaling is too "under-constrained to be a reliable

\footnotetext{
${ }^{7}$ In an important work, Poole (1998) analyzes real valued data of this latter type in its original rectangular (voters by issues, for example) format with a variant of singular value decomposition with iterative aspects for the estimation of missing values. The procedure avoids the difficulty of pre-processing this rectangular matrix into a symmetric matrix of similarity coefficients or covariances, which, as we've indicated, can be a source of some analytical problems. It also works remarkably well, recovering the correct dimensionality of simulated data under even extreme rates of error and missing data. As the procedure is currently designed for real valued data, rather than binary, it is not however directly applicable to the issues at hand. If it were adapted to binary data, or if the data were pre-processed into real-valued scores (perhaps with the W-NOMINATE procedure used by Poole; see also Poole and Rosenthal, 1997), it could prove useful for solving the problems associated with analyzing the voting patterns of all Justices from multiple natural courts simultaneously, which we have not attempted here.
} 
discovery procedure" (p. 274). It is too likely to produce scales when in fact no underlying unidimensional variable exists and, conversely, the failure to find a good Guttman scale does not rule out the possibility that such a variable does exist. Apparently, scholars in political science seem to have reached much the same conclusion, as their preference ever since has been mostly to use some variant of factor analysis. Kronenfeld himself happens to suggest "MDS programs (such as those of Shepherd and Kruskal or Torgerson)" (p. 274).

One other obvious possible approach to scaling this type of data is correspondence analysis (CA). CA is essentially a form of metric scaling intended originally to correct for the effects of unequal marginal totals in contingency tables or indicator matrices (Fisher, 1940; Guttman, 1941). Its advantage in this original use is that it allow users to scale both rows and columns of a two-way matrix into the same multi-dimensional space. Recent advances, however, have allowed its application to non-frequency data, such as airline distances, the cognitive similarity of items within a semantic domain, and social proximities (Benzecri, 1992; Brazill et al., 1995; Gifi, 1990; Gittins, 1980; Greenacre, 1984; Kumbasar, 1994; Kumbasar et al., 1994; Nishisato, 1980, 1994; Romney et al., 1995, 1996, 1998; Weller and Romney, 1990). CA is in fact closely akin to factor analysis, having the same singular-value decomposition at its heart, and only differing in pre- and post-processing (see Weller and Romney, 1990 for a discussion of its relation to other metric scaling techniques). As such, however, it is also apparently susceptible to the same types of difficulties as factor analysis. Weller and Romney (1990), in demonstrating its use on frequency of artifacts over different layers of an archeological site (which theoretically might be unidimensional), produce the now familiar curvilinear "horseshoe effect" (p. 78-79). They also use CA to solve a Guttman-scale type problem of recovering the order of acquisition of various household goods among villages in Polynesia. The basic structure of the original data in this case is very similar to that examined in this paper. Each household item is coded in a binary fashion for its presence at each of the villages, just as we have a set of justices and a number of binary votes. For this type of data Weller and Romney suggest using a multi-way indicator matrix, where each item has a double column of scores, coded for both its presence and absence in each village. Nevertheless, when they submit this matrix to CA, they again recover "the horseshoe effect characteristic of ordered data" (p. 80). Similarly, preliminary applications of CA to the data in Table 1, in its raw form, as a multi-way indicator matrix and as a square matrix of phi coefficients $(8 \times 8$, again), all produced obvious curvilinearity in the first two-dimensions. As was the case with the principal components factor analysis, submitting the $9 \times 9$ matrix of simple matching coefficients reduces the curvilinearity, but it is still noticeable. The only clear improvement over the factor analysis results is that the scores associated with the largest non-trivial singular value (i.e. the first dimension) coincide with the "correct" ordering of the voters, and the curvature occurs in the second dimension.

Another recent development in the use of CA that might be relevant to this discussion is the work of Carroll et al. (1997), who develop another set of pre- and post-processing operations which allows CA to perfectly recover two-dimensional Euclidean data and is asymptotically equivalent to MMDS. In this case, however, the input data are not the actual Euclidean distances between the voter ideal points on the underlying dimension(s), but rather we have only the series of binary votes for each voter to try to distinguish their position. It is not clear at this point that we should expect this variant of CA, thus, to recover appropriate inter-voter distances, and preliminary analyses have not resulted in the types of 
perfect fit we found with MDS. Further work is clearly required to assess the relative merits of CA for this type of data.

\section{Acknowledgements}

We are indebted to Clover Behrend, Dorothy Green and Jesse Knepper for library assistance, and to A. Kimball Romney, Professor of Anthropology, University of California, Irvine and J. Douglas Carroll, Bell Laboratories, for helpful bibliographic citations to the literatures on MDS (and related approaches) in anthropology and psychology, respectively. We also appreciate the comments of the editor of this volume and two anonymous reviewers.

\section{References}

Alwin, D.F., 1973. The use of factor analysis in the construction of linear composites in social research. Sociological Methods and Research 2, 191-214.

Arrow, K., 1961. Social Change and Individual Values. Wiley, New York, NY.

Batchelder, W., Romney, A.K., 1988. Test theory without an answer key. Psychometrika 53 (1), 71-92.

Benzecri, J.-P., 1992. Correspondence Analysis Handbook. Marcel-Dekker, New York, NY.

Bernard, J., 1955. Dimensions and axes of Supreme Court decisions: a study in the sociology of conflict. Social Forces 34, 19-27.

Black, D., 1958. The Theory of Committees and Elections. Cambridge University Press, Cambridge, MA.

Bowler, S., Grofman, B., 2000. Elections in Australia, Ireland, and Malta under the Single Transferable Vote. University of Michigan Press, Ann Arbor, MI.

Brams, S.J., Fishburn, P.C., 1983. Approval Voting. Birkhaeuser, Cambridge, MA.

Brazill, T.J., Romney, A.K., Batchelder, W.H., 1995. A comparison of methods for collecting judged similarities among items in a semantic domain. Journal of Quantitative Anthropology 5, 359-374.

Budge, I., Fairlie, D.J., 1983. Explaining and Predicting Elections: Issue Effects and Party Strategies in Twenty-three Democracies. Allen and Unwin, Boston, MA.

Budge, I., Robertson, D., Hearl, D. (Eds.), 1987. Ideology, Strategy and Party Change: Spatial Analysis of Post-war Election Programmes in 19 Democracies. Cambridge University Press, Cambridge, MA.

Carroll, J.D., Kumbasar, E., Romney, A.K., 1997. An equivalence relation between correspondence analysis and classical metric multidimensional scaling for the recovery of Euclidean distances. British Journal of Mathematical and Statistical Psychology 50 (1), 81-92.

Cattell, R.B., 1952. Factor Analysis: An Introduction and Manual for the Psychologist and Social Scientist. Harper, Reprinted by Greenwood Press, 1973, New York, NY.

Cattell, R.B., 1965. Factor analysis: an introduction to the essentials: (I) the purpose and underlying models. (II) the role of factor analysis in research, Biometrics 21, 190-215, 405-435.

Christofferson, A., 1975. Factor analysis of dichotomized variables. Psychometrika 40 (1), 5-32.

Clausen, A., 1973. How Congressmen Decide: A Policy Focus. St. Martin's Press, New York, NY.

Coleman, J., Ferejohn, J., 1986. Democracy and social choice. Ethics 97 (1), 6-25.

Coombs, C.H., 1964. A Theory of Data. Wiley, New York.

Coombs, C.H., Kao, R.C., 1960. On a connection between factor analysis and multi-dimensional unfolding. Psychometrika 25, 219-231.

Coxon, A.P.M., 1982. The User's Guide to Multi-dimensional Scaling: With Special Reference to the MDS(x) Library of Computer Programs. Heinemann, London.

Davis, A., Gardner, B.B., Gardner, M.R., 1941. Deep South. University of Chicago Press, Chicago, IL.

Davison, M.L., 1977. On a metric, unidimensional unfolding model for attitudinal and developmental data. Psychometrika 42, 523-548.

Downs, A., 1957. An Economic Theory of Democracy. Harper, New York, NY. 
Ducat, C.R., Dudley, R.L., 1987. Dimensions underlying economic policymaking in the early and later Burger Courts. Journal of Politics 49, 521-539.

Dudley, R.L., Ducat, C.R., 1986. The Burger Court and economic liberalism. Western Political Quarterly 39, 236-249.

Enelow, J.M., Hinich, M., 1984. The Spatial Theory of Voting: An Introduction. Cambridge University Press, New York, NY.

Feld, S.L., Grofman, B., 1988. Ideological consistency as a collective phenomenon. American Political Science Review 82 (3), 64-75.

Feld, S.L., Grofman, B., 1990. Collectivities as actors. Rationality and Society 2 (4), 429-448.

Fisher, R.A., 1940. The precision of discriminant functions. Annals of Eugenics 10, 422-429.

Gifi, A., 1990. Nonlinear Multivariate Analysis. Wiley, Leiden, The Netherlands.

Gittins, R., 1980. Canonical Analysis: A Review with Applications in Ecology. Springer, Berlin, Germany.

Greenacre, M.J., 1984. Theory and Applications of Correspondence Analysis. Academic Press, London, UK.

Grofman, B., 1975. A comment on Democratic theory: a preliminary mathematical model. Public Choice 21, $100-103$.

Grofman, B., Feld, S.L., 1988. Rousseau's general will: a Condorcetian perspective. American Political Science Review 82 (2), 567-577.

Grofman, B., Brazill, T., in press. Identifying the Median Justice on the Supreme Court Through Multi-dimensional Scaling: Analysis of the Natural Courts, 1953-1991, Public Choice.

Grofman, B., Owen, G., Feld, S.L., 1983. Thirteen theorems in search of the truth. Theory and Decision 15, 261-278.

Guttman, L., 1941. The quantification of a class of attributes: a theory and method of scale construction. In: Horst, P., et al. (Eds.), The Prediction of Personal Adjustment. The Social Science Research Council, Bulletin No. 48. New York, NY, pp. 319-348.

Guttman, L., 1944. A basis for scaling qualitative data. American Sociological Review 9, 139-150.

Guttman, L., 1950a. The Basis for Scalogram Analysis. In: Stouffer, S.A., Guttman, L., Suchman, E., Lazarsfeld, P.E., Star, S.A., Gardner, J.A. (Eds.), Measurement and Prediction. Princeton University Press, Princeton, NJ, pp. 60-90.

Guttman, L., 1950b. The principal components of scale analysis. In: Stouffer, S.A., Guttman, L., Suchman, E., Lazarsfeld, P.E., Star, S.A., Gardner, J.A. (Eds.), Measurement and Prediction. Princeton University Press, Princeton, NJ.

Guttman, L., 1954a. The principal components of scalable attitudes. In: Lazarsfeld, P.F. (Ed.), Mathematical Thinking in the Social Sciences. Free Press, Glencoe, pp. 216-257.

Guttman, L., 1954b. A new approach to factor analysis: the radex. In: Lazarsfeld, P.F. (Ed.), Mathematical Thinking in the Social Sciences. Free Press, Glencoe, pp. 258-348.

Guttman, L., 1958. What lies ahead for factor analysis? Educational and Psychological Measurement 18, 497-515.

Guttman, L., 1966. Order analysis of correlation matrices. In: Cattell, R.B. (Ed.), Handbook of Multivariate Experimental Psychology. Rand McNally, Chicago, IL, pp. 438-458.

Guttman, L., 1982. Facet theory, smallest space analysis, and factor analysis. Perceptual and Motor Skills 54, 491-493.

Guttman, R., Shoham, I., 1982. Structure of spatial ability items: a faceted analysis, perceptual . Perceptual and Motor Skills 54 (2), 487-491.

Harman, H.H., 1960. Modern Factor Analysis. University of Chicago Press, Chicago, IL.

Homans, G.C., 1951. The Human Group. Harcourt, Brace and Co., New York, NY, 1992.

Hotelling, H., 1933. Analysis of a complex of statistical variables into principal components, Journal of Educational Psychology 24, 417-441, 498-520.

Hubert, L.J., Arabie, P., 1988. Relying on necessary conditions for optimization: unidimensional scaling and some extensions. In: Bock, H.-H. (Ed.), Classification and Related Methods of Data Analysis. North-Holland, Amsterdam, pp. 463-472.

Kaiser, H.F., 1974. An index of factorial simplicity. Psychometrika 39, 31-36.

Kim, J.O., Mueller, C.W., 1978. Factor Analysis: Statistical Methods and Practical Issues, Sage University Paper series in Quantitative Applications in the Social Sciences, 07-014. Sage, Beverly Hills, CA.

Koford, K., 1989. Dimensions in congressional voting. American Political Science Review 83 (3), 949-962. 
Koford, K., 1990. Dimensions, transactions costs and coalitions in legislative voting. Economics and Politics 2 (1), 59-82.

Koford, K., 1991. On dimensionalizing roll-call votes in the United-States Congress. American Political Science Review 85 (3), 955-975.

Koford, K., 1994. What can we learn about congressional politics from dimensional studies of roll-call voting? Economics and Politics 6 (2), 173-186.

Kronenfeld, D.B., 1972. Guttman scaling: problems of conceptual domain, unidimensionality, and historical inference. Man 7 (2), 255-276.

Kruskal, J.B., 1964a. Multi-dimensional scaling by optimizing goodness of fit to a nonmetric hypothesis. Psychometrika 29 (1), 1-27.

Kruskal, J.B., 1964b. Nonmetric multi-dimensional scaling: a numerical example. Psychometrika 29 (2), $115-129$.

Kruskal, J.B., Wish, M., 1978. Multi-dimensional Scaling, Sage University Series on Quantitative Applications in the Social Sciences, 07-011. Sage, Beverly Hills, CA.

Kumbasar, A.E., 1994. Ego biases in cognitive representations of social structures. Ph.D. dissertation. School of Social Sciences, University of California, Irvine.

Kumbasar, A.E., Romney, A.K., Batchelder, W.H., 1994. Systematic biases in social perception. American Journal of Sociology $100(1), 477-505$.

Levin, J., Montag, I., Comrey, A.L., 1983. Comparison of multi-trait-multi-method, factor, and smallest space analysis on personality scale data. Psychological Reports 53, 591-596.

Lingoes, J.C., Guttman, L., 1967. Non-metric factor analysis: a rank-reducing alternative to linear factor analysis. Multivariate Behavioral Research 2, 485-505.

Macdonald, S.E., Listhaug, O., Rabinowitz, G., 1991. Issues and party support in multi-party systems. American Political Science Review 85 (4), 1107-1131.

MacRae, Jr., D., 1970. Issues and Parties in Legislative Voting: Methods of Statistical Analysis. Harper and Row, New York, NY.

MacRae, Jr., D., Goldner, F.H., 1958. Dimensions of Congressional Voting: A Statistical Study of the House of Representatives in the Eighty-first Congress. University of California Press, Berkeley, CA.

Masolavty, N., Marshall, A.E., Alkin, M.C., 2001. Teachers' perceptions structured through facet theory: smallest space analysis versus factor analysis . Educational and Psychological Measurement 61 (1), 71-84.

Neimi, R.G., Weisberg, H., 1974. Single peakedness and Guttman scales: concept and measurement. Public Choice 20, 33-45.

Nishisato, S., 1980. Analysis of Categorical Data: Dual Scaling and Its Applications. University of Toronto Press, Toronto, Canada.

Nishisato, S., 1994. Elements of Dual Scaling. Erlbaum, Mahwah, New Jersey.

Poole, K.T., 1998. Recovering a basic space from a set of issue scales. American Journal of Political Science 42 (3), 954-993.

Poole, K.T., Rosenthal, H., 1984. The polarization of American politics. Journal of Politics 46, 1061-1079.

Poole, K.T., Rosenthal, H., 1991. Patterns of congressional voting. American Journal of Political Science 35, 228-278.

Poole, K.T., Rosenthal, H., 1997. Congress: A Political-Economic History of Roll Call Voting. Oxford University Press, New York, NY.

Regenwetter, M., Grofman, B., 1998a. Choosing subsets: a size-independent probabilistic model and the quest for a social welfare ordering. Social Choice and Welfare 15 (3), 423-443.

Regenwetter, M., Grofman, B., 1998b. Approval voting, borda winners, and condorcet winners: evidence from seven elections. Management Science 44 (4), 520-533.

Regenwetter, M., Falmagne, J.-C., Grofman, B., 1999. A stochastic model of preference change and its application to 1992 Presidential election panel data. Psychological Review 106 (2), 362-384.

Roberts, J.S., Laughlin, 1996. A unidimensional item response model for unfolding responses from a graded disagree-agree response scale, Applied Psychological Measurement 20, (3) 231-255.

Rohde, D.W., Spaeth, H.J., 1976. Supreme Court Decision-Making. Freeman, San Francisco, CA.

Romney, A.K., Weller, S.C., Batchelder, W.H., 1986. Culture as consensus: a theory of culture and informant accuracy. American Anthropologist 99 (2), 313-338.

Romney, A.K., Batchelder, W.H., Weller, S.C., 1987. Recent applications of cultural consensus theory. American Behavioral Scientist 3 (2), 163-177. 
Romney, A.K., Batchelder, W.H., Brazill, T.J., 1995. Scaling semantic domains. In: D. Luce, et al. (Eds.), Geometric Representations of Perceptual Phenomena: Papers in Honor of Tarow Indow on His 70th Birthday. Erlbaum, New Jersey, pp. 267-294.

Romney, A.K., Boyd, J.P., Moore, C.C., Batchelder, W.H., Brazill, T.J., 1996. Culture as shared cognitive representations. In: Proceedings of the National Academy of Sciences, Vol. 93. pp. 4699-4705.

Romney, A.K., Moore, C.C., Brazill, T.J., 1998. Correspondence analysis as a multi-dimensional scaling technique for non-frequency similarity matrices. In: Greenacre, M., Blasius, J. (Eds.), Visualization of Categorical Data. Academic Press, San Diego, CA, pp. 329-345.

Ross, J., Cliff, N., 1964. A generalization of the interpoint distance model. Psychometrika 29 (2), 167-176.

Schlesinger, I.M., Guttman, L., 1969. Smallest space analysis of intelligence and achievement tests. Psychological Bulletin 71, 95-100.

Schubert, G., 1965. The Judicial Mind. Northwestern University Press, Evanston, IL.

Schubert, G., 1974. The Judicial Mind Revisited. Oxford University Press, London.

Shepard, R.N., 1962a. Analysis of proximities: multi-dimensional scaling with an unknown distance function. I. Psychometrika 27, 125-140.

Shepard, R.N., 1962b. Analysis of proximities: multi-dimensional scaling with an unknown distance function. II. Psychometrika 27, 219-246.

Shepard, R.N., 1974. Representation of structure in similarity data: problems and prospects. Psychometrika 39 (4), $373-421$.

Shepard, R.N., Romney, A.K., Nerlove, S.B. (Eds.), 1972a. Multi-dimensional Scaling, Volume I: Theory. Seminar Press, New York, NY.

Shepard, R.N., Romney, A.K., Nerlove, S.B. (Eds.), 1972b. Multi-dimensional Scaling, Volume II: Applications in the Behavioral Sciences. Seminar Press, New York, NY.

Spaeth, H., 1993. United States Supreme Court Judicial Database: 1953-1991 Terms, ICPSR 9422 4th Release. International Consortium for Political and Social Research, Ann Arbor, MI.

Taagepera, R., Shugart, M.S., 1989. Seats and Votes: The Effects and Determinants of Electoral Systems. Yale University Press, New Haven, CT.

Torgerson, W.S., 1958. Theory and Methods of Scaling, Wiley, New York, NY.

Ulmer, S.S., 1960. The analysis of behavior patterns in the Supreme Court of the United States. Journal of Politics $22,429-447$.

Ulmer, S.S., 1970. Dissent behavior and the social background of Supreme Court Justices. Journal of Politics 32, $580-598$.

Van Schuur, W.H., 1984. Structure in Political Beliefs: A New Model for Stochastic Unfolding With Application to European Party Activists. CT Press, Amsterdam.

Van Schuur, W.H., Kiers, H.A.L., 1994. Why factor analysis often is the incorrect model for analyzing bipolar concepts, and what model to use instead, and what model to use instead. Applied Psychological Measurement 18 (2), 97-110.

Weisberg, H.F., 1974. Dimensionland: an excursion into spaces. American Journal of Political Science 18 (4), $743-776$.

Weisberg, H.F., 1980. A multi-dimensional conceptualization of party identification. Political Behavior 2 (1), 33-60.

Weller, S.C., Romney, A.K., 1990. Metric Scaling: Correspondence Analysis, Sage University Series on Quantitative Applications in the Social Sciences 07-075. Sage, Newbury Park, CA.

Wilcox, W.C., Clausen, A., 1991. The dimensionality of roll-call voting reconsidered. Legislative Studies Quarterly 16 (3), 393-406.

Wilkinson, L., 1990. SYSTAT, Vol. 5.0: The System for Statistics, Manual \& Computer program. SYSTAT Inc., Evanston, IL. 